Article

\title{
Nanomaterial Gas Sensors for Online Monitoring System of Fruit Jams
}

\author{
Estefanía Núñez-Carmona ${ }^{1}\left(\mathbb{D}\right.$, Marco Abbatangelo ${ }^{2, *}{ }^{\circledR}$, Ivano Zottele ${ }^{3}$, Pierpaolo Piccoli ${ }^{3}$, \\ Armando Tamanini ${ }^{3}$, Elisabetta Comini ${ }^{2,4}{ }^{\mathbb{D}}$, Giorgio Sberveglieri ${ }^{4}$ and \\ Veronica Sberveglieri ${ }^{1,4}$ D \\ 1 CNR-IBBR, Institute of Bioscience and Bioresources, via Madonna del Piano, 10, 50019 Sesto Fiorentino, FI, \\ Italy; estefania.nunezcarmona@ibbr.cnr.it (E.N.-C.); veronica.sberveglieri@ibbr.cnr.it (V.S.) \\ 2 Department of Information Engineering, University of Brescia, Brescia, via Branze, 38, 25123 Brescia, BS, \\ Italy; elisabetta.comini@unibs.it \\ 3 Menz\&Gasser S.p.A., Sede Legale Zona Industriale, 38050 Novaledo (TN), Italy; \\ ivano.zottele@menz-gasser.it (I.Z.); pierpaolo.piccoli@menz-gasser.it (P.P.); \\ armando.tamanini@menz-gasser.it (A.T.) \\ 4 Nano Sensor Systems, NASYS Spin-Off University of Brescia, Brescia, via Camillo Brozzoni, 9, 25125 Brescia, \\ BS, Italy; giorgio.sberveglieri@nasys.it \\ * Correspondence: m.abbatangelo@unibs.it; Tel.: +39-3488-423-503
}

Received: 4 November 2019; Accepted: 22 November 2019; Published: 2 December 2019

check for updates

\begin{abstract}
Jams are appreciated worldwide and have become a growing market, due to the greater attention paid by consumers for healthy food. The selected products for this study represent a segment of the European market that addresses natural products without added sucrose or with a low content of natural sugars. This study aims to identify volatile organic compounds (VOCs) that characterize three flavors of fruit and five recipes using gas chromatography-mass spectrometry (GC-MS) and solid-phase micro-extraction (SPME) analysis. Furthermore, an innovative device, a small sensor system (S3), based on gas sensors with nanomaterials has been used; it may be particularly advantageous in the production line. Results obtained with linear discriminant analysis (LDA) show that S3 can distinguish among the different recipes thanks to the differences in the VOCs that are present in the specimens, as evidenced by the GC-MS analysis. Finally, this study highlights how the thermal processes for obtaining the jam do not alter the natural properties of the fruit.
\end{abstract}

Keywords: volatile organic compounds (VOCs); gas chromatography-mass spectrometry (GC-MS); jams; chemical sensors; nanowire gas sensors; linear discriminant analysis (LDA)

\section{Introduction}

The term "marmalade" comes from the Portuguese "marmelo," which means "quince tree". This method to preserve fruits was already appreciated in the times of the ancient Greeks, who had discovered that the pulp of fruits, acrid and almost inedible, once cooked became very sweet with a strong scent of honey. Hence "quince" which in Greek means "apple of honey".

The decree 20 February 2004 n $^{\circ} 50$ implementation of Directive 2001/113/EC concerning jams of the European community defines it as "the mixture brought to a suitable gelled consistency of sugars and pulp of one or more species of fruit and water. It is a particular type of food preserve. The fruit, according to the law, must be fresh, intact and healthy, at the right point of maturation, clean and blunt; the roots of the ginger, tomato, rhubarb (limited to the edible parts of the stems), carrots, cucumbers, pumpkins, melons, and watermelons are equated to the fruit" [1].

Fruit jams are a growing market. In the last year, the export value of the countries that market in this sector was approximately $\$ 3.2$ billion. In this scenario, European countries have "the lion's share," 
with a turnover linked to exports of $\$ 2$ billion—equal to $61.1 \%$ of the global total—followed by Asian producers $(20.2 \%)$, those in Latin America (9.3\%), North America (5.6\%), Africa (2.7\%) and Oceania $(1.1 \%)[2]$.

In Europe, Italy is the second largest exporter of jams (8.4\% of total exports worth $\$ 270.3$ million market), preceded by France (12\%) and followed by Turkey (8\%) [2]. An explanation for this success is probably the desire of consumers to search for natural and simple products and those that, if possible, are also good for health. The growth in market value appears to be driven above all by the sector of jams without added sugar. Also, in the jam or marmalade market, as in general in many food markets, we are witnessing a shift towards increasing trade and purchase of "healthy" and less processed products, with clean ingredient lists and lower sugar content. The greater attention to diet products and increased awareness of the need to fight diseases such as diabetes with prevention are increasingly pushing the offer towards high-added-value light products.

Research on the volatile compounds of food aims to provide the characterization of aromatic profiles, thus allowing the identification of the most important compounds in defining the characteristics of the product $[3,4]$. The main components of food (proteins, amino acids, carbohydrates, lipids, and fatty acids) undergo degradation processes following conservation processes (e.g., seasoning) or due technological treatments (e.g., cooking), and thus arise a wide range of compounds such as hydrocarbons, esters, aldehydes, ketones, alcohols, nitrogen and sulfur compounds, which impart the characteristic aroma to the food [5-7].

The determination of volatile substances in food plays a role of considerable importance: these substances are in fact responsible for the aroma of the product, which can fall within the norms of acceptability and even be a peculiar characteristic of the product or anomalies due to the presence of substances which impart an unpleasant smell-the so-called "off-flavors" with chemical or microbiological origin [4]. It is therefore particularly important to identify and quantify the compounds normally present in the volatile fraction of food products in order to characterize the aromatic profile and to study the variations depending on, for example, the geographical origin, production technology, seasoning, ripening or interaction with the packaging material $[8,9]$.

Volatile compounds can be extracted using different sampling techniques, both classic and innovative, such as dynamic headspace and solid-phase microextraction. In this study, both will be used in parallel. In fact, they will constitute the fundamental database that will pave the base for the algorithm design that will constitute the neural network capable of supporting the production process of jams.

Although very precise, the analysis methods currently used, are costly in terms of expensive instrumentation, at the time of analysis as well as to obtain a result, without neglecting the need to have prepared technical personnel [10-15]. The rapid methods currently available are instead still considered unsatisfactory, both due to the long analysis time and to the poor reliability and high costs. For many technologies currently in use, the high-speed response often recalls a lack of sensitivity or accuracy.

Currently, to the authors' knowledge, just a few articles in the literature have dealt with the evolution of volatile compounds in food products of this type. For this reason, it is not only important to identify new rapid technologies and devices to support the production of high quality, but also to increase knowledge on their aromatic product to better understand the evolution that can occur during the cooking of the fruit used as raw material. As a result, interest in new technologies based on chemical sensor arrays [16] has grown in recent years. Ample interest has been demonstrated by the numerous scientific publications that are distributed both between classes of foods such as meats, vegetables, cereals, etc., but also between raw materials and finished and packaged products, following the entire production chain from the fields to the fork. Applications take into consideration geographical origins, production anomalies, supply chain checks or possible chemical and physical contamination of the matrix [17-19]. 
The aim of this study is to provide the characterization of the aromatic profile of jams, thus allowing the identification of compounds that most contribute to the identification of a particular product. In summary, this study will characterize the volatile compounds emitted by different jams using gas chromatography-mass spectrometry (GC-MS) with solid-phase micro-extraction (SPME) analysis. The jams used will be representative of both different flavors (the type of fruit used) and different recipes (types and percentage of ingredients). In addition, we will try to identify an innovative technique based on nanowire gas sensors, which can be an advantageous online decision-making aid to the business transformation process.

\section{Materials and Methods}

\subsection{Experiment Design}

The research works were carried out following three steps. Firstly, the volatile organic compound (VOC) determination of fruit jams was carried out with GC-MS and SPME analysis (for details, see Section 2.2). Secondly, a small sensor system (S3) nanowire gas sensor device was developed and optimized (details see Section 2.3) in our lab with collaboration with the NANO SENSOR SYSTEMS Srl spin-off of the University of Brescia, Italy. The measures used in parallel, in this study, are shown in Figure 1.

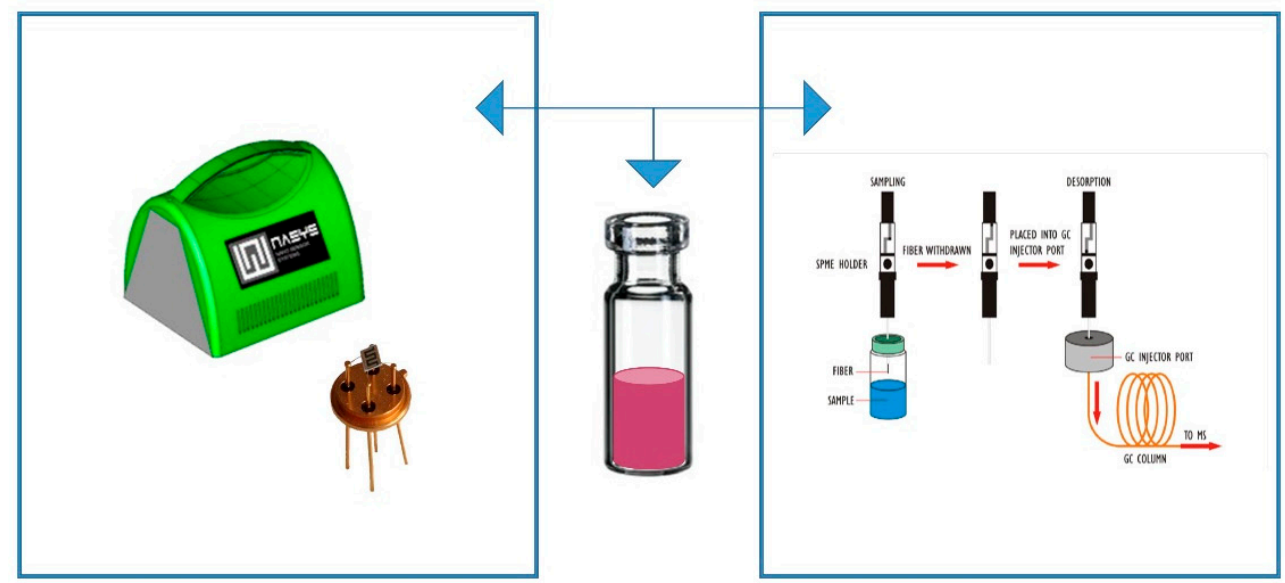

Figure 1. Illustration of online control of fruit jam by using a small sensor system (S3) device (left) and gas chromatography-mass spectrometry (GC-MS) and solid-phase micro-extraction (SPME) (right).

In Table 1 flavors (strawberry, apricot, and cherry) with their recipes are shown. Samples were prepared under sterilized conditions. In total, $10 \mathrm{~g}$ of a sample was placed in a sterilized vial, sealed with septa made of polytetrafluoroethylene (PTFE)/silicone. Once closed, the samples were placed at room temperature for 1 hour before being analyzed in order to create a balanced headspace inside the vial. Vials, septa, syringes and all the material used for the preparation of the samples were sterilized in an autoclave at $121^{\circ} \mathrm{C}$ for $15 \mathrm{~min}$, in order to eliminate any kind of cross-microbiological contamination, which could alter the characteristic volatile organic compounds (VOCs) of the product, for the duration of the analysis. Samples used were treated and prepared for both techniques, exactly in the same way, to try to reduce the variables related to the preparation as much as possible. The operational conditions were interpreted in Sections 2.3 and 2.4, respectively. 
Table 1. List of samples analyzed: 3 flavors and 5 recipes for each taste.

\begin{tabular}{|c|c|c|}
\hline Taste & Sample Code & Ingredients \\
\hline \multirow{5}{*}{ Apricot } & APS & $\begin{array}{l}\text { Apricots; grape sugar; gelling agent: pectin; acidity correctors: citric acid and } \\
\text { calcium citrate. Fruit used } 70 \text { g per } 100 \mathrm{~g} .\end{array}$ \\
\hline & $\mathrm{AL}$ & $\begin{array}{c}\text { Apricots; apple sugar; gelling agent: pectin; acidity corrector: calcium citrate. } \\
\text { Fruit used } 50 \mathrm{~g} \text { per } 100 \mathrm{~g} .\end{array}$ \\
\hline & AS & $\begin{array}{l}\text { Apricots; fructose; water; gelling agent: pectin; acidity corrector: citric acid; } \\
\text { calcium citrate; sweetener: steviol glycosides. Fruit used: } 50 \text { g per } 100 \mathrm{~g} .\end{array}$ \\
\hline & A100 & $\begin{array}{l}\text { Apricots; grape sugar; concentrated lemon juice; gelling agent: fruit pectin. } \\
\text { Used apricots: } 100 \mathrm{~g} \text { per } 100 \mathrm{~g} \text { of product. }\end{array}$ \\
\hline & AVL & $\begin{array}{l}\text { Apricots; sugar; gelling agent: pectin; acidity correctors: citric acid and } \\
\text { calcium citrate; sweetener: steviol glycosides. Fruit used } 70 \text { g per } 100 \mathrm{~g} \text {. }\end{array}$ \\
\hline \multirow{5}{*}{ Strawberry } & SPS & $\begin{array}{l}\text { Strawberry; grape sugar; gelling agent: pectin; acidity corrector: citric acid; } \\
\text { concentrated elderberry juice. Fruit used } 70 \text { g per } 100 \mathrm{~g} .\end{array}$ \\
\hline & SL & $\begin{array}{l}\text { Strawberries; apple sugar; gelling agent: pectin; acidity corrector: citric acid } \\
\text { and calcium citrate; red fruit juice; concentrated elderberry juice. Fruit used } \\
50 \mathrm{~g} \text { per } 100 \mathrm{~g} .\end{array}$ \\
\hline & SS & $\begin{array}{l}\text { Strawberries; fructose; water; gelling agent: pectin; acidity corrector: citric } \\
\text { acid and calcium citrate; concentrated elderberry juice; sweetener: steviol } \\
\text { glycosides. Fruit used: } 50 \mathrm{~g} \text { per } 100 \mathrm{~g} \text {. }\end{array}$ \\
\hline & S100 & $\begin{array}{l}\text { Strawberries; grape sugar; gelling agent: pectin; concentrated lemon juice; } \\
\text { concentrated elderberry juice. Used strawberries: } 100 \text { g per } 100 \mathrm{~g} \text { of product. }\end{array}$ \\
\hline & SVL & $\begin{array}{l}\text { Strawberries; sugar; gelling agent: pectin; acidity correctors: citric acid and } \\
\text { calcium citrate; concentrated elderberry juice; sweetener: steviol glycosides. } \\
\text { Fruit used } 70 \mathrm{~g} \text { per } 100 \mathrm{~g} .\end{array}$ \\
\hline \multirow{5}{*}{ Cherry } & CPS & $\begin{array}{l}\text { Cherries; sugar; concentrated lemon juice; gelling agent: pectin; acidity } \\
\text { corrector: calcium citrate. Fruit used } 50 \text { g per } 100 \mathrm{~g} \text { of product. }\end{array}$ \\
\hline & CL & $\begin{array}{c}\text { Cherries; apple sugar; gelling agent: pectin; acidity correctors: citric acid and } \\
\text { calcium citrate. Fruit used } 50 \mathrm{~g} \text { per } 100 \mathrm{~g} .\end{array}$ \\
\hline & CS & $\begin{array}{l}\text { Cherries; fructose; water; gelling agent: pectin; acidity corrector: citric acid } \\
\text { and calcium citrate; sweetener: steviol glycosides. Fruit used: } 50 \mathrm{~g} \text { per } 100 \mathrm{~g} \text {. }\end{array}$ \\
\hline & C100 & $\begin{array}{l}\text { Cherries; grape sugar; concentrated lemon juice; gelling agent: fruit pectin. } \\
\text { Used cherries: } 100 \text { g per } 100 \mathrm{~g} \text { of product. }\end{array}$ \\
\hline & CVL & $\begin{array}{l}\text { Cherries; sugar; gelling agent: pectin; acidity correctors: citric acid and } \\
\text { calcium citrate; sweetener: steviol glycosides. Fruit used } 70 \text { g per } 100 \mathrm{~g} \text {. }\end{array}$ \\
\hline
\end{tabular}

\subsection{GC-MS SPME Detection}

One hour after closure, vials were placed in the autosampler HT280T (HTA s.r.l., Brescia, Italy) to proceed with vial conditioning and volatile organic compound (VOC) extraction. Conditioning of the sample was performed as follows: filled vials where maintained for $15 \mathrm{~min}$ at $40{ }^{\circ} \mathrm{C}$ in order to equilibrate the headspace (HS) of the sample and to remove any variables. Afterward, VOC extraction was performed using solid-phase microextraction (SPME) analysis and the fiber used for the adsorption of volatiles was a divinylbenzene/carboxen/polydimethylsiloxane (DVB/CAR/PDMS) $50 / 30 \mu \mathrm{m}$ (Supelco Co. Bellefonte, PA, USA) placed on the HT280T autosampler. The fiber was exposed to the vial HS in the HT280T oven thermostatically regulated at $40^{\circ} \mathrm{C}$ for $30 \mathrm{~min}$.

The GC instrument used in this work was a Shimadzu GC 2010 PLUS (Kyoto, KYT, Japan), equipped with a Shimadzu single quadrupole mass spectrometer (MS) MS-QP2010 Ultra (Kyoto, KYT, Japan). Fiber desorption took place in the GC-MS injector for $6 \mathrm{~min}$ at $250{ }^{\circ} \mathrm{C}$. GC was operated in the direct mode throughout the run, while the separation was performed on a MEGA-WAX capillary column, $30 \mathrm{~m} \times 0.25 \mathrm{~mm} \times 0.25 \mu \mathrm{m}$, (Agilent Technologies, Santa Clara, CA, USA). Ultrapure helium $(99.99 \%)$ was used as the carrier gas, at a constant flow rate of $1 \mathrm{~mL} / \mathrm{min}$. The GC oven temperature programming was applied as follows: at the beginning, the chromatographic column was held at $40^{\circ} \mathrm{C}$ 
for $2 \mathrm{~min}$ and, subsequently, the temperature was raised from 40 to $70{ }^{\circ} \mathrm{C}$ at $5{ }^{\circ} \mathrm{C} / \mathrm{min}$, and held for 1 min. Next, the temperature was raised from 90 to $240{ }^{\circ} \mathrm{C}$, with a rate of $10^{\circ} \mathrm{C} / \mathrm{min}$; finally, $240{ }^{\circ} \mathrm{C}$ was maintained for $4 \mathrm{~min}$, for a total program time of $30 \mathrm{~min}$ [20-22].

During the analysis, the GC-MS interface was kept at $200^{\circ} \mathrm{C}$, with the mass spectrometer in the electron ionization (EI) mode $(70 \mathrm{eV})$ and related to instrument tuning, and the ion source was kept at $200{ }^{\circ} \mathrm{C}$. Mass spectra were collected over 35 to $500 \mathrm{~m} / \mathrm{z}$ in range in the total ion current (TIC) mode, with scan intervals at $0.3 \mathrm{~s}$. VOC identification was carried out using the NIST11 and the FFNSC2 libraries of mass spectra.

Chromatogram peak integration was performed using the peak area as target parameter programming an automatic integration round using 70 as the minimum number of peak detection and 500 as the minimum area to detect. Other parameters used in the automatic peak integration were: slope 100/min, width $2 \mathrm{~s}$, drift 0/min, doubling time (T.DBL) $1000 \mathrm{~min}$, and no smoothing method was applied. The final round of peak integration was performed by manual peak integration for all the obtained chromatograms.

\subsection{S3 Detection}

$\mathrm{S} 3$ is an acronym for small sensor systems, which is a device developed by the collaboration of the groups involved in this study. S3 was previously used, with considerable success, in numerous studies applied to the field of food technology and quality control [23,24]. S3 consists of an electronic part to manage the signal, in order to send acquired data to the cloud, where it is possible to store and analyze them; an element that allows its connection to the internet; a pump to bring the volatile compounds to the heart of the instrument, as shown in Figure 2.

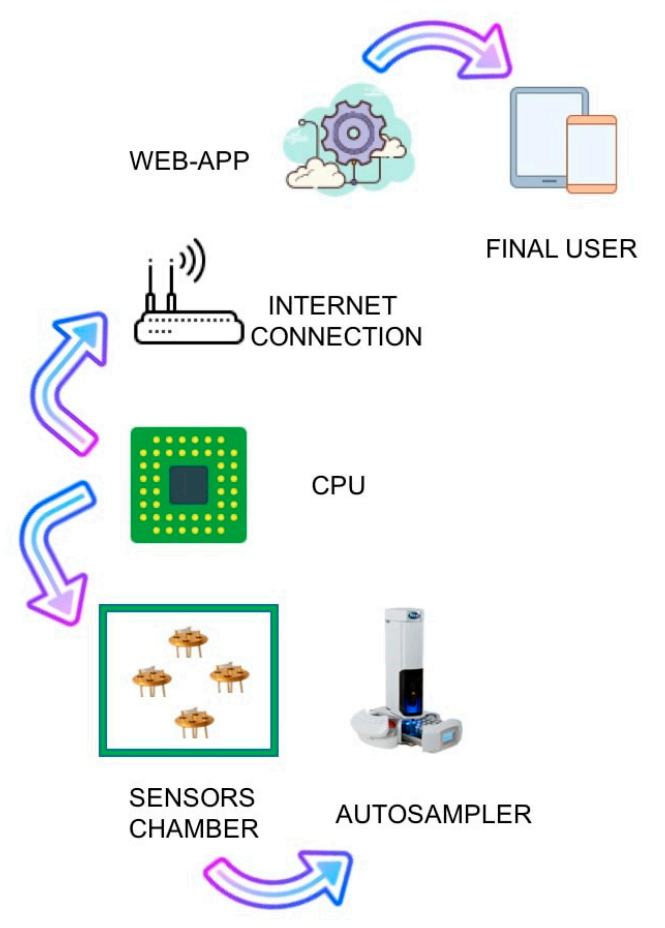

Figure 2. Diagram representing S3 device components.

The volatile compounds collected by a pneumatic pump are conveyed inside an autosampler HT280T, supporting a 42-loading site carousel, (HTA s.r.l., Brescia, Italy), able to reduce the possible variables due to the preparation of the sample. The autosampler, used for the $\mathrm{S} 3$ device is the same model also used to prepare the samples seen in Section 2.2 associated with the GC-MS. S3 is equipped with an array of chemiresistor type sensors. The sensors grown and developed for this work were created with two techniques, Rheotaxial Growth Thermal Oxidation (RGTO) and nanowire technology. 
The RGTO technique involves two deposition steps: the first stage of a metallic thin film by DC magnetron sputtering from a metallic target on a substrate at higher temperatures than the melting point of the metal, then the thermal oxidation cycle in order to get a metal oxide layer with stable stoichiometry [25]. The surface of the thin film is rough, and this is an advantage since it provides a high surface-to-volume ratio and reactivity with gaseous species [26]. In addition, the existence of such very rough surface morphology, usually named 'spongy agglomerates', gives rise to a high specific area required for high-sensitivity gas sensors [27].

Nanowires exhibit exceptional crystalline quality and a very high length-to-width ratio, subsequent in enhanced sensitivity as well as long-term material stability for prolonged operation $[28,29]$. The experimental process consists of the evaporation of the powder (metal oxide) at high temperatures in a controlled atmosphere at pressures lower than hundreds of mbar (50-200 mbar) and the following mass transport of the vapor (50-100 sccm) towards the substrates kept at lower temperatures with respect to the source evaporation region. This growth technique is called the vapor-liquid-solid (VLS) mechanism. For $\mathrm{SnO}_{2}$ sensors, powders are positioned in the center of the furnace at $1370{ }^{\circ} \mathrm{C}$, then an inert air flow at temperatures between 350 and $500{ }^{\circ} \mathrm{C}$ is used as carrier from furnace to substrates, where nanowires start growing.

Regarding $\mathrm{CuO}$ sensors, a thin layer of metallic copper was deposited on target substrates by RF magnetron sputtering, with a constant gas flow kept at $7 \mathrm{sccm}$. Copper is very reactive in environmental atmosphere, and the interaction with oxygen spontaneously produces a thin layer of copper oxide that must be removed to allow the growth of nanowires. After copper oxide layer removal, the sensors undergo a forced oxidation in a carbolite tubular furnace for $15 \mathrm{~h} \mathrm{[30].}$

The list of the 5 sensors produced at Sensor Lab and used for this study is presented in Table 2. The other 4 sensors were commercial sensors-MQ2, MQ3, TGS2611 and TGS2602.

Table 2. List of sensors produced at Sensors Lab, University of Brescia.

\begin{tabular}{ccc}
\hline Materials & Morphology & Working Temperature $\left({ }^{\circ} \mathbf{C}\right)$ \\
\hline $\mathrm{SnO}_{2}+\mathrm{Au}$ & RGTO & 400 \\
$\mathrm{SnO}_{2}$ & $\mathrm{RGTO}$ & 400 \\
$\mathrm{CuO}$ & Nanowire & 350 \\
$\mathrm{SnO}_{2}+\mathrm{Au}$ & Nanowire & 350 \\
$\mathrm{SnO}_{2}$ & Nanowire & 350 \\
\hline
\end{tabular}

RGTO, Rheotaxial Growth Thermal Oxidation.

In Table 3, a list of replicas analyzed for each sample is reported. Again, from the table, the number of total measures for each flavor is 45 for apricot, 34 for strawberry, and 37 for cherry.

Table 3. List of samples analyzed with an S3 device, divided for the different recipes.

\begin{tabular}{ccc}
\hline Taste & Sample Code & Number of Replicas for S3 \\
\hline \multirow{4}{*}{ Apricot } & APS & 10 \\
& AL & 10 \\
& AS & 11 \\
& A100 & 7 \\
& AVL & 7 \\
\hline \multirow{3}{*}{ Strawberry } & SPS & 6 \\
& SL & 7 \\
& SS & 6 \\
& S100 & 9 \\
SVL & 6 \\
\hline \multirow{3}{*}{ Cherry } & CPS & 6 \\
& CL & 10 \\
& CS 100 & 7 \\
& CVL & 7 \\
\hline
\end{tabular}




\subsection{Data Analysis Methods}

From GC-MS analysis, a list of all the VOCs of the samples was found. The aim of this study was to find which compounds were in common for different recipes of the same flavor. Common VOCs were obtained comparing VOC lists obtained from GC-MS analysis, considering all the recipes for every single fruit. Only VOCs present in all the recipes were considered and shown in the following tables.

S3 analysis output consists of the resistance variation of the sensor due to VOC analysis. First, sensor responses in terms of resistance $(\Omega)$ were normalized when compared to the first value of the acquisition (R0). For all the sensors, the difference between the first value and the minimum value during the analysis time was calculated; hence, $\Delta \mathrm{R} / \mathrm{R} 0$ has been extracted as featured. For each taste, a specific matrix has been created: the rows contain all the measures for that taste considering all the recipes, the columns features are extracted from the sensors array.

Linear discriminant analysis (LDA) was applied to the three matrices built in this way. LDA is a well-known supervised technique for the dimensionality reduction of a dataset or classification purposes. Its aim is to minimize intra-class variability and to maximize separation between classes. Hence, LDA was used to determine whether the recipes could be distinguished by sensors. To calculate the accuracies of recipe recognition, venetian blinds was used as a cross validation method dividing each dataset in 10 folds.

\section{Results and Discussion}

In this section, the results obtained during this study will be presented. All the results obtained in the phase of the identification and analysis of volatile compounds (VCs) with GC-MS and SPME analysis will be used for the creation of the database and for training through artificial intelligence of the S3 device.

\subsection{Determination of VOCs}

The results obtained from the characterization of the jams of $t$ three flavors and five analyzed recipes will be presented below. The results obtained are representative of three replicas for each of the recipes and flavors analyzed, for a total of:

\section{3 flavor $\times 5$ recipe $\times 3$ replicas $=45$ samples}

All the compounds presented in the table were found in all three replicas of all the five recipes analyzed, belonging to the strawberry, apricot and cherry taste (Tables 4-6). The table below will highlight the individual contributions of the individual compounds with the characteristic smell of the analyzed jams. The abundance work shown in the table is obtained by averaging the three replicas of each sample.

The characteristic odor of fruits and of the production process is not influenced by the recipe and the raw materials used to obtain it. This also highlights the naturalness of the analyzed product, which does not compromise the real characteristics of fruits. 
Table 4. List of the compounds identified in all the strawberry recipes.

\begin{tabular}{|c|c|c|c|c|c|c|c|}
\hline Retention Time & Compound & SPS & SVL & S100 & SL & ss & Description \\
\hline 11.343 & Acetoin & $5.90 \times 10^{5}$ & $9.62 \times 10^{5}$ & $6.90 \times 10^{5}$ & $7.36 \times 10^{5}$ & $1.40 \times 10^{6}$ & $\begin{array}{l}\text { Pleasant, buttery odor. Acetoin is used as a food flavoring (in baked goods) and } \\
\text { as a fragrance. It can be found in apples, butter, yogurt, asparagus, } \\
\text { blackcurrants, blackberries, wheat, broccoli, brussels sprouts, cantaloupes and } \\
\text { maple [31]. }\end{array}$ \\
\hline 14.527 & Linalool oxide & $6.66 \times 10^{5}$ & $8.44 \times 10^{5}$ & $1.72 \times 10^{6}$ & $7.97 \times 10^{5}$ & $1.23 \times 10^{6}$ & $\begin{array}{l}\text { Furanoid with floral odor type, and musty, camphoreous, herbal, balsamic, and } \\
\text { pine notes. Other name: 2-(5-ethenyl-5-methyloxolan-2-yl) propan-2-yl ethyl } \\
\text { carbonate (IUPAC) [32]. }\end{array}$ \\
\hline 14.689 & Ammonium acetate & $6.16 \times 10^{6}$ & $6.77 \times 10^{6}$ & $7.92 \times 10^{6}$ & $4.18 \times 10^{6}$ & $6.22 \times 10^{6}$ & $\begin{array}{l}\text { Slight odor of acetic acid. Its use as a food additive regulator of acidity is } \\
\text { authorized in Australia and New Zealand, where it is identified by the number } \\
\text { INS } 264 \text { and in the European Union where it is identified by the code E264 [33]. }\end{array}$ \\
\hline 14.931 & Furfural & $2.27 \times 10^{7}$ & $1.07 \times 10^{7}$ & $1.88 \times 10^{7}$ & $1.23 \times 10^{7}$ & $1.35 \times 10^{7}$ & $\begin{array}{l}\text { The compound is an aldehyde group attached to the 2-position of furan. It is a } \\
\text { product of the acid catalyzed dehydration of five-carbon sugars (pentoses), } \\
\text { particularly xylose. These sugars may be obtained from hemicellulose present in } \\
\text { lignocellulosic biomass, which can be extracted from most terrestrial plants. It is } \\
\text { found in many foods: coffee ( } 55-255 \mathrm{mg} / \mathrm{kg} \text { ) and whole-grain bread ( } 26 \mathrm{mg} / \mathrm{kg} \text { ). } \\
\text { When heated in the presence of acids, furfural irreversibly polymerizes, acting } \\
\text { as a thermosetting polymer [34]. }\end{array}$ \\
\hline 15.585 & $\begin{array}{l}\text { Ethanone and } \\
\text { 1-(2-furanyl)- }\end{array}$ & $1.94 \times 10^{6}$ & $1.08 \times 10^{6}$ & $1.67 \times 10^{6}$ & $1.48 \times 10^{6}$ & $9.83 \times 10^{5}$ & $\begin{array}{c}\text { It is found in alcoholic beverages. It is present in cooked apples, marasca cherry, } \\
\text { wine grapes, peach, strawberry, plum, blueberry, asparagus, kohlrabi, baked } \\
\text { potatoes, pineapple, bread products, rice, yogurt, wines, soy, and black tea. It } \\
\text { contributes to the aroma of many foods and beverages. It is used in aromatic } \\
\text { compositions. Another name: 2-acetylfuran [35]. }\end{array}$ \\
\hline 15.893 & Benzaldehyde & $4.65 \times 10^{6}$ & $3.64 \times 10^{6}$ & $1.55 \times 10^{7}$ & $1.24 \times 10^{7}$ & $2.34 \times 10^{7}$ & $\begin{array}{c}\text { Benzaldehyde has a role as a flavoring agent, fragrance and a plant metabolite. } \\
\text { Benzaldehyde can be derived from natural sources and is colorless liquid that } \\
\text { turns to brown on exposure to air. It is an aromatic aldehyde that carries a single } \\
\text { formyl group with an almond smell. Benzaldehyde was first extracted from } \\
\text { bitter almonds [36]. }\end{array}$ \\
\hline 16.159 & $\begin{array}{l}\text { 1,6-octadien-3-ol and } \\
\text { 3,7-dimethyl- }\end{array}$ & $1.50 \times 10^{7}$ & $9.20 \times 10^{6}$ & $9.33 \times 10^{6}$ & $2.35 \times 10^{6}$ & $3.87 \times 10^{6}$ & $\begin{array}{l}\text { Known as linalool, it is a monoterpene abundantly present in the essence of } \\
\text { rosewood. It is also found free or combined in the natural essential oils of } \\
\text { coriander, basil, lavender or bergamot. It has an antimicrobial effect and it is } \\
\text { present in the total pull of volatile organic compounds (VOCs) of many fruits } \\
\text { and flowers. It is confirmed that linalool is the most important compound for } \\
\text { strawberry flavor [37,38]. }\end{array}$ \\
\hline 16.921 & $\begin{array}{l}\text { 3(2H)-furanone and } \\
\text { 4-methoxy-2,5-dimethyl- }\end{array}$ & $2.56 \times 10^{6}$ & $2.39 \times 10^{6}$ & $2.25 \times 10^{6}$ & $9.20 \times 10^{5}$ & $6.99 \times 10^{5}$ & $\begin{array}{l}\text { Furanone methyl ether typical of strawberries. Nice, caramelic, sweet moldy } \\
\text { mushroom, vegetable potato, burnt sugar, nut skin, wasabi, fruity, brandy with } \\
\text { cocoa and coffee notes [39]. }\end{array}$ \\
\hline
\end{tabular}


Table 4. Cont

\begin{tabular}{|c|c|c|c|c|c|c|c|}
\hline Retention Time & Compound & SPS & SVL & S100 & SL & SS & Description \\
\hline 17.769 & Acetophenone & $4.31 \times 10^{6}$ & $6.67 \times 10^{5}$ & $1.52 \times 10^{6}$ & $8.89 \times 10^{5}$ & $1.21 \times 10^{6}$ & $\begin{array}{l}\text { It is the simplest aromatic ketone and an ingredient in fragrances that resemble } \\
\text { almond, cherry, honeysuckle, jasmine, and strawberry. It is used in chewing } \\
\text { gum. It is also listed as an approved excipient by the U.S. Food and Drug } \\
\text { Administration (FDA) [40]. }\end{array}$ \\
\hline 17.944 & $\begin{array}{l}\text { Butanoic acid and } \\
\text { 2-methyl- }\end{array}$ & $1.94 \times 10^{6}$ & $2.87 \times 10^{6}$ & $3.27 \times 10^{6}$ & $1.59 \times 10^{6}$ & $1.78 \times 10^{6}$ & $\begin{array}{l}\text { (S)-2-Methylbutyric acid has a pleasantly sweet, fruity odor. } \\
\text { (R)-2-methylbutanoic acid has a pervasive, cheesy, and sweaty odor [41]. }\end{array}$ \\
\hline 18.305 & L- $\alpha$-terpineol & $4.53 \times 10^{6}$ & $4.02 \times 10^{6}$ & $1.15 \times 10^{7}$ & $1.47 \times 10^{6}$ & $2.98 \times 10^{6}$ & $\begin{array}{l}\alpha \text {-Terpineol is a monoterpene alcohol that has been isolated from a variety of } \\
\text { sources such as cajuput oil, pine oil, and petitgrain oil. It has a characteristic } \\
\text { lilac odor, with a sweet taste reminiscent of peach on dilution. It is found in the } \\
\text { composition of various essential oils }[39,42] \text {. }\end{array}$ \\
\hline 20.141 & Heptanoic acid & $2.58 \times 10^{6}$ & $2.85 \times 10^{6}$ & $3.32 \times 10^{6}$ & $1.24 \times 10^{6}$ & $2.65 \times 10^{5}$ & $\begin{array}{l}\text { It makes part of flavoring agents and related substances. Cheese and other } \\
\text { dairy-type flavors, and ripe fruit especially apple and strawberry [43]. }\end{array}$ \\
\hline 20.573 & Benzyl alcohol & $3.59 \times 10^{5}$ & $6.02 \times 10^{5}$ & $2.44 \times 10^{6}$ & $2.85 \times 10^{5}$ & $5.73 \times 10^{5}$ & $\begin{array}{l}\text { Benzyl alcohol is an aromatic alcohol and a colorless liquid with a mild pleasant } \\
\text { aromatic odor. It is a component of some essential oils such as jasmine, neroli, } \\
\text { violet and ylang-ylang. It can be used as a preservative [44]. }\end{array}$ \\
\hline 20.975 & Phenylethyl alcohol & $5.90 \times 10^{5}$ & $2.00 \times 10^{5}$ & $4.36 \times 10^{5}$ & $2.22 \times 10^{5}$ & $4.96 \times 10^{5}$ & $\begin{array}{l}\text { Also known as 2-phenylethanol, it is an organic compound that consists of a } \\
\text { phenethyl group attached to an OH group. It is a colorless liquid that is widely } \\
\text { available in nature, found in a variety of essential oils. It has a pleasant floral } \\
\text { odor [45]. }\end{array}$ \\
\hline 22.531 & Octanoic acid & $3.00 \times 10^{5}$ & $2.40 \times 10^{5}$ & $2.87 \times 10^{5}$ & $4.04 \times 10^{5}$ & $3.98 \times 10^{5}$ & $\begin{array}{l}\text { Octanoic acid is a volatile organic acid detected in strawberry jam at a conc of } \\
\qquad 2.9 \mathrm{mg} / \mathrm{kg} \text {. [44,46]. }\end{array}$ \\
\hline 23.573 & $\begin{array}{l}\text { 2(3H)-furanone and } \\
\text { 5-hexyldihydro- }\end{array}$ & $2.78 \times 10^{6}$ & $3.14 \times 10^{6}$ & $3.30 \times 10^{6}$ & $7.91 \times 10^{5}$ & $1.06 \times 10^{6}$ & A furan compound linked to a ketone group with a fruity peach flavor [40]. \\
\hline 26.429 & Benzoic acid & $4.52 \times 10^{5}$ & $7.12 \times 10^{5}$ & $7.84 \times 10^{5}$ & $3.39 \times 10^{5}$ & $4.74 \times 10^{6}$ & $\begin{array}{l}\text { A simple aromatic carboxylic acid that occurs naturally in many plants and } \\
\text { serves as an intermediate in the biosynthesis of many secondary metabolites, } \\
\text { and it is found in post-harvested strawberries up to } 29 \mathrm{mg} / \mathrm{kg} \mathrm{[47].}\end{array}$ \\
\hline
\end{tabular}

SPS, SVL, S100, SL, SS: sample code. 
Table 5. List of the compound identified in all the apricot recipes.

\begin{tabular}{|c|c|c|c|c|c|c|c|}
\hline Retention Time & Compound & APS & AVL & A100 & $\mathrm{AL}$ & AS & Description \\
\hline 6.130 & Hexanal & $2.53 \times 10^{5}$ & $1.99 \times 10^{6}$ & $8.99 \times 10^{5}$ & $8.03 \times 10^{5}$ & $2.12 \times 10^{6}$ & $\begin{array}{l}\text { Also called hexanaldehyde or caproaldehyde, it is an alkyl aldehyde. Its scent } \\
\text { resembles freshly cut grass, with a powerful, penetrating characteristic fruity } \\
\text { odor and taste. It occurs naturally and contributes a hay-like "off-note" flavor in } \\
\text { green peas }[21,39,48] \text {. }\end{array}$ \\
\hline 6.707 & Linalool oxide & $1.21 \times 10^{6}$ & $9.72 \times 10^{5}$ & $5.27 \times 10^{6}$ & $7.54 \times 10^{5}$ & $1.56 \times 10^{6}$ & $\begin{array}{l}\text { Furanoid with floral odor type, with musty, camphoreous, herbal, balsamic, and } \\
\text { pine notes. Linaloil oxide is found in alcoholic beverages. It is an aromatic and } \\
\text { fragrant ingredient. Linaloile oxide is present in roselle tea, muscat grapes, lime } \\
\text { oil, alfalfa, Riesling wine, grapefruit, yellow passion fruit, apricot, blackberry, } \\
\text { blueberry, and nectarine. Other name: 2-(5-ethenyl-5-methyloxolan-2-yl) } \\
\text { propan-2-yl ethyl carbonate (IUPAC) [32]. }\end{array}$ \\
\hline 11.964 & Cyclohexanone, 2,2,6-trimethyl- & $5.02 \times 10^{5}$ & $4.54 \times 10^{5}$ & $8.28 \times 10^{5}$ & $4.63 \times 10^{5}$ & $9.01 \times 10^{5}$ & $\begin{array}{l}\text { Found in bilberries, passion fruit and tea. Also found in apricot, bilberry, white } \\
\text { wine, black tea, green tea, microbial fermented tea, brewed tea, yellow passion } \\
\text { fruit juice and dill herb [40]. }\end{array}$ \\
\hline 12.523 & 5-Hepten-2-one, 6-methyl- & $1.37 \times 10^{6}$ & $1.69 \times 10^{6}$ & $2.13 \times 10^{6}$ & $1.25 \times 10^{6}$ & $1.84 \times 10^{6}$ & $\begin{array}{l}\text { Also known as sulcatone, it is an unsaturated methylated ketone with a } \\
\text { citrus-like, fruity odor. Sulcatone is one of a number of mosquito attractants and } \\
\text { has been also found in apricot scent }[39,49] \text {. }\end{array}$ \\
\hline 14.931 & Furfural & $3.52 \times 10^{7}$ & $1.46 \times 10^{7}$ & $5.87 \times 10^{7}$ & $2.40 \times 10^{7}$ & $4.37 \times 10^{7}$ & $\begin{array}{l}\text { The compound is an aldehyde group attached to the 2-position of furan. It is a } \\
\text { product of the acid catalyzed dehydration of five-carbon sugars (pentoses), } \\
\text { particularly xylose. These sugars may be obtained from hemicellulose present in } \\
\text { lignocellulosic biomass, which can be extracted from most terrestrial plants. It is } \\
\text { found in many foods: coffee ( } 55-255 \mathrm{mg} / \mathrm{kg} \text { ) and whole-grain bread ( } 26 \mathrm{mg} / \mathrm{kg} \text { ). } \\
\text { When heated in the presence of acids, furfural irreversibly polymerizes, acting } \\
\text { as a thermosetting polymer [34,39]. }\end{array}$ \\
\hline 15.881 & Benzaldehyde & $3.08 \times 10^{6}$ & $2.64 \times 10^{6}$ & $5.58 \times 10^{6}$ & $3.03 \times 10^{6}$ & $7.65 \times 10^{6}$ & $\begin{array}{l}\text { A colorless liquid that turns to brown on exposure to air. Benzaldehyde has a } \\
\text { characteristic odor and aromatic taste, similar to bitter almond, and is also } \\
\text { produced during the ripening of apricots }[39,50] \text {. }\end{array}$ \\
\hline 16.143 & 1,6-Octadien-3-ol, 3,7-dimethyl- & $3.03 \times 10^{7}$ & $2.66 \times 10^{7}$ & $3.27 \times 10^{7}$ & $3.80 \times 10^{6}$ & $4.83 \times 10^{6}$ & $\begin{array}{c}\text { Known as linalool, it is a monoterpene abundantly present in the essence of } \\
\text { rosewood. It is also found free or combined in the natural essential oils of } \\
\text { coriander, basil, lavender or bergamot. It has an antimicrobial effect and it is } \\
\text { present in the total pull of volatile organic compounds (VOCs) of many flowers } \\
\text { and fruits such as apricots }[39,48] .\end{array}$ \\
\hline
\end{tabular}


Table 5. Cont.

\begin{tabular}{|c|c|c|c|c|c|c|c|}
\hline Retention Time & Compound & APS & AVL & A100 & $\mathbf{A L}$ & AS & Description \\
\hline 16.605 & 2-Furancarboxaldehyde, 5-methyl- & $8.24 \times 10^{5}$ & $2.51 \times 10^{5}$ & $1.56 \times 10^{6}$ & $5.97 \times 10^{5}$ & $1.42 \times 10^{6}$ & $\begin{array}{l}\text { Organic compounds known as aryl-aldehydes; it contains an aldehyde group } \\
\text { directly attached to an aromatic ring. It is found in pepper (c. annuum). The } \\
\text { 5-methyl-2-furancarboxaldehyde is isolated from brown algae and other plant } \\
\text { sources, doubtless as a secondary produced from saccharides }[39,48,50] \text {. }\end{array}$ \\
\hline 16.974 & $\begin{array}{l}\text { 3-Cyclohexen-1-ol, } \\
\text { 4-methyl-1-(1-methylethyl)-, (R)- }\end{array}$ & $6.27 \times 10^{5}$ & $1.13 \times 10^{6}$ & $1.35 \times 10^{6}$ & $6.28 \times 10^{5}$ & $8.61 \times 10^{5}$ & $\begin{array}{l}\text { It is also known as 4-terpineol and is a flavoring ingredient found in the aroma } \\
\text { of apricots. It has a role as a plant metabolite, antibacterial agent, antioxidant, } \\
\text { anti-inflammatory agent, and antiparasitic agent [51]. }\end{array}$ \\
\hline 18.247 & L- $\alpha$-Terpineol & $1.76 \times 10^{7}$ & $1.97 \times 10^{7}$ & $3.94 \times 10^{7}$ & $4.16 \times 10^{6}$ & $1.08 \times 10^{7}$ & $\begin{array}{l}\alpha \text {-Terpineol is a monoterpene alcohol that has been isolated from a variety of } \\
\text { sources such as cajuput oil, pine oil, and petitgrain oil. It has a characteristic } \\
\text { lilac odor with a sweet taste reminiscent of peach on dilution. It is found in the } \\
\text { composition of various essential oils }[39,42,51] \text {. }\end{array}$ \\
\hline 20.703 & 4-Acetyl-1-methylcyclohexene & $2.59 \times 10^{5}$ & $3.23 \times 10^{5}$ & $7.88 \times 10^{5}$ & $1.18 \times 10^{5}$ & $2.21 \times 10^{5}$ & $\begin{array}{l}\text { It is found in cereals and cereal products. The 4-Acetyl-1-methylcyclohexene is a } \\
\text { flavoring ingredient. It is isolated from the famine food Santalum album } \\
\text { (sandalwood) [48]. }\end{array}$ \\
\hline 21.252 & trans-.beta.-Ionone & $9.88 \times 10^{5}$ & $1.26 \times 10^{6}$ & $1.44 \times 10^{6}$ & $8.17 \times 10^{5}$ & $1.12 \times 10^{6}$ & $\begin{array}{l}\beta \text {-Ionone has a characteristic violet-like odor, and is fruitier and woodier than } \\
\qquad \text {-ionone. }\end{array}$ \\
\hline 26.326 & Benzoic acid & $4.44 \times 10^{5}$ & $7.11 \times 10^{5}$ & $9.42 \times 10^{5}$ & $2.70 \times 10^{5}$ & $1.53 \times 10^{7}$ & $\begin{array}{l}\text { It is a simple aromatic carboxylic acid that occurs naturally in many plants and } \\
\text { serves as an intermediate in the biosynthesis of many secondary metabolites. It } \\
\text { is found during the ripening of apricots [50] and in post-harvest strawberries up } \\
\text { to } 29 \mathrm{mg} / \mathrm{kg} \text { [47]. }\end{array}$ \\
\hline
\end{tabular}


Table 6. List of the compound identified in all the cherry recipes.

\begin{tabular}{|c|c|c|c|c|c|c|c|}
\hline Retention Time & Compound & CPS & CVL & C100 & CL & CS & Description \\
\hline 13.630 & Nonanal & $1.18 \times 10^{6}$ & $3.49 \times 10^{5}$ & $2.11 \times 10^{5}$ & $1.08 \times 10^{5}$ & $1.90 \times 10^{5}$ & $\begin{array}{l}\text { Nonanal has a strong, fatty odor, developing an orange and rose note on } \\
\text { dilution. It has a fatty, citrus-like flavor }[39,40,52] \text {. }\end{array}$ \\
\hline 14.943 & Furfural & $5.77 \times 10^{6}$ & $9.86 \times 10^{6}$ & $7.46 \times 10^{6}$ & $1.51 \times 10^{7}$ & $1.26 \times 10^{7}$ & $\begin{array}{l}\text { The compound is an aldehyde group attached to the } 2 \text {-position of furan. It is a } \\
\text { product of the acid catalyzed dehydration of five-carbon sugars (pentoses), } \\
\text { particularly xylose. These sugars may be obtained from hemicellulose present in } \\
\text { lignocellulosic biomass, which can be extracted from most terrestrial plants. It is } \\
\text { found in many foods: coffee ( } 55-255 \mathrm{mg} / \mathrm{kg} \text { ) and whole-grain bread ( } 26 \mathrm{mg} / \mathrm{kg} \text { ) } \\
\text { When heated in the presence of acids, furfural irreversibly polymerizes, acting } \\
\text { as a thermosetting polymer [34,39,40]. }\end{array}$ \\
\hline 15.881 & Benzaldehyde & $1.04 \times 10^{7}$ & $4.14 \times 10^{6}$ & $2.52 \times 10^{6}$ & $4.84 \times 10^{7}$ & $8.93 \times 10^{7}$ & $\begin{array}{l}\text { Benzaldehyde has a role as a flavoring agent, fragrance and a plant metabolite. } \\
\text { It is an aromatic aldehyde that carries a single formyl group. Benzaldehyde can } \\
\text { be derived from natural source and is colorless liquid that turns to brown on } \\
\text { exposure to air. Benzaldehyde has a characteristic odor and aromatic taste, } \\
\text { similar to bitter almond, and is also produced during the ripening of apricots } \\
\text { and cherries }[36,39,50,52] \text {. }\end{array}$ \\
\hline 16.155 & $\begin{array}{l}\text { 1,6-Octadien-3-ol, } \\
\text { 3,7-dimethyl- }\end{array}$ & $1.87 \times 10^{6}$ & $2.42 \times 10^{6}$ & $1.83 \times 10^{6}$ & $1.05 \times 10^{6}$ & $1.18 \times 10^{6}$ & $\begin{array}{c}\text { Known as linalool, it is a monoterpene abundantly present in the essence of } \\
\text { rosewood. It is also found free or combined in the natural essential oils of } \\
\text { coriander, basil, lavender or bergamot. It has an antimicrobial effect and is } \\
\text { present in the total pull of VOCs of many flowers and fruits as apricots and } \\
\text { cherries }[39,48,52] \text {. }\end{array}$ \\
\hline 18.264 & L- $\alpha$-Terpineol & $2.01 \times 10^{7}$ & $1.07 \times 10^{6}$ & $7.82 \times 10^{6}$ & $1.20 \times 10^{6}$ & $1.63 \times 10^{6}$ & $\begin{array}{l}\alpha \text {-Terpineol is a monoterpene alcohol that has been isolated from a variety of } \\
\text { sources such as cajuput oil, pine oil, and petitgrain oil. It has a characteristic } \\
\text { lilac odor, with a sweet taste reminiscent of peach on dilution. It is found in the } \\
\text { composition of various essential oils }[39,42,51,52] \text {. }\end{array}$ \\
\hline 26.307 & Benzoic acid & $5.70 \times 10^{5}$ & $5.87 \times 10^{5}$ & $3.24 \times 10^{5}$ & $2.09 \times 10^{5}$ & $2.30 \times 10^{6}$ & $\begin{array}{l}\text { It is a simple aromatic carboxylic acid that occurs naturally in many plants and } \\
\text { serves as an intermediate in the biosynthesis of many secondary metabolites. It } \\
\text { is found during the ripening of apricots [50] and in post-harvest strawberries up } \\
\text { to } 29 \mathrm{mg} / \mathrm{kg} \text { [47]. }\end{array}$ \\
\hline
\end{tabular}




\subsection{E-Nose Performance}

Chemical sensors used in this work have the peculiarity to change their resistance once they are exposed to pure gases or mixtures, such as VOCs. In Figure 3, the trends of four sensors from the array are shown for apricot measures and for all the recipes. In particular, all the graphs have time indication in seconds on the $\mathrm{x}$-axis and on normalized resistance the $\mathrm{y}$-axis; this is the reason why all signals start from a value equal to 1 . Once sensing materials react with VOCs, resistance decreases. This reduction changes from sensor to sensor: indeed, each sensor reaches a different minimum resistance and the shape of the signals are diverse, too. Furthermore, focusing on a single sensor, it can be observed that sensors respond differently to the five recipes. Taking the $\mathrm{RGTO}-\mathrm{SnO}_{2} \mathrm{Au}$ sensor as an example, the samples APS, AVL and AL are more similar in respect to A100 and AS. Otherwise, TGS2611 sensor signals show that A100 samples are more different from the other four types. This is the main reason why sensors arrays are used since metal oxide (MOX) sensors are non-specific sensors and respond to a broad range of molecules. In that way, it is possible to distinguish among the recipes taking into account information coming from different sources.
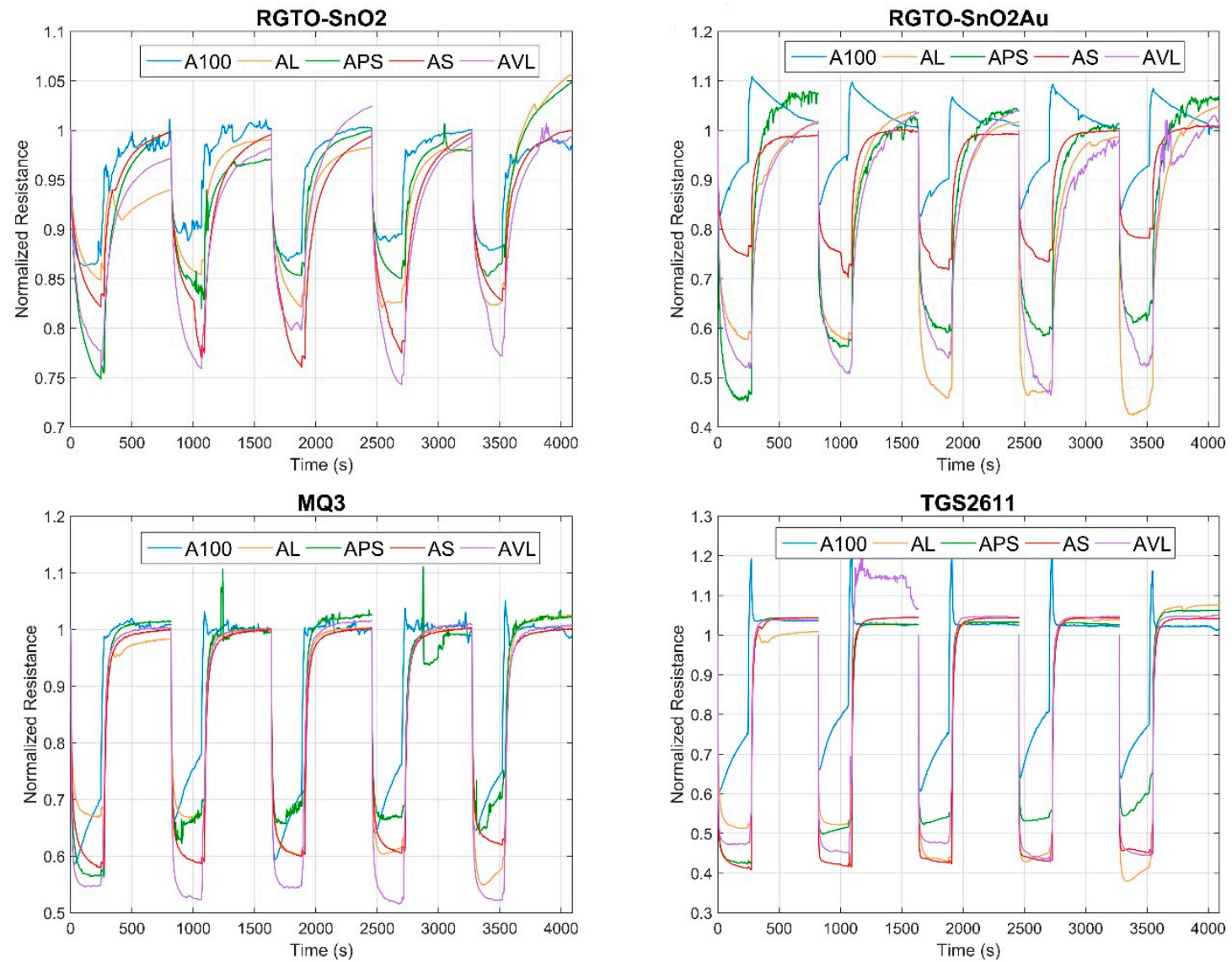

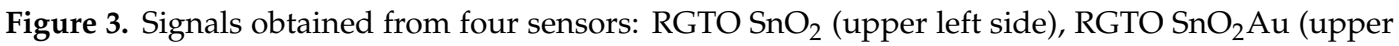
right side), MQ3 (low left side), and TGS2611 (low right side). Five measures are shown as an example of the typical sensor responses to apricot.

When VOC exposition ends, filtrated ambient air is fluxed to restore the sensor baseline. The baseline is recovered when resistance value returns close to the value 1 , as shown in the normalized graphs of Figure 3. At the end of VOC analysis, the needle of the autosampler that aspires headspace sample comes out of the vial and this can produce an abrupt change of pressure in the flow that arrives in the sensor chamber. This can cause a sudden change in the response, as it can be observed for A100 measures in RGTO-SnO ${ }_{2} \mathrm{Au}$ and TGS2611 sensors. However, after the overshoot, signals tend to converge to the value of 1 . 
From signal observation, it has been decided that $\Delta \mathrm{R} / \mathrm{R} 0$ could be a feature suitable for our purposes. Three matrices have been built with these values-one for each fruit. LDA was applied to each dataset to determine how different classes (i.e., recipes) cluster. In Figure 4, the LDA graph with the first two linear discriminants (LDs) is shown, for a total explained variance (EV) equal to $94.45 \%$. That means that almost all the information carried by features has been useful to discriminate between the classes. The graph shows that the A100 and AS samples are very different in respect to the others. On the contrary, the AL, APS and AVL clusters are closer but they do not overlap. This can be explained looking at the compounds obtained from the GC-MS analysis. Lists of all VOCs can be found in Appendix A (Tables A1-A15). The quantities of common VOCs compared to the total of compounds considering each recipe varies from $64.65 \%$ to $76.33 \%$. This difference does not explain the reason why the five groups cluster in the way shown in Figure 4 . All recipes have furfural, $\alpha$-terpineol, 1,6-octadien-3-ol, 3,7-dimethyl- and benzaldehyde among the first six most abundant compounds; these are also compounds that are present in all the recipes as shown in Table 4. The AS aromatic profile differs from the other because it has ammonium acetate (instead of acetic acid like the other recipes) and acetone among the compounds with the highest quantities, and a bigger area of the peak of benzoic acid $(11.11 \%$ of relative abundance, while it is between $0.33 \%$ and $0.75 \%$ for the other four recipes). Regarding A100, it has 2H-pyran, 2-ethenyltetrahydro-2,6,6-trimethyl- (2.5\%, in the other recipes is between $0.91 \%$ and $1.19 \%)$ naphthalene, and 1,2,3,4-tetrahydro-1,1,6-trimethyl- (2.2\%, while it is between $0.37 \%$ and $0.48 \%$ for the others; it is absent in AL samples) within the top ten most present compounds. Calculation of LDA performances led to obtain an accuracy of $93.48 \%$.

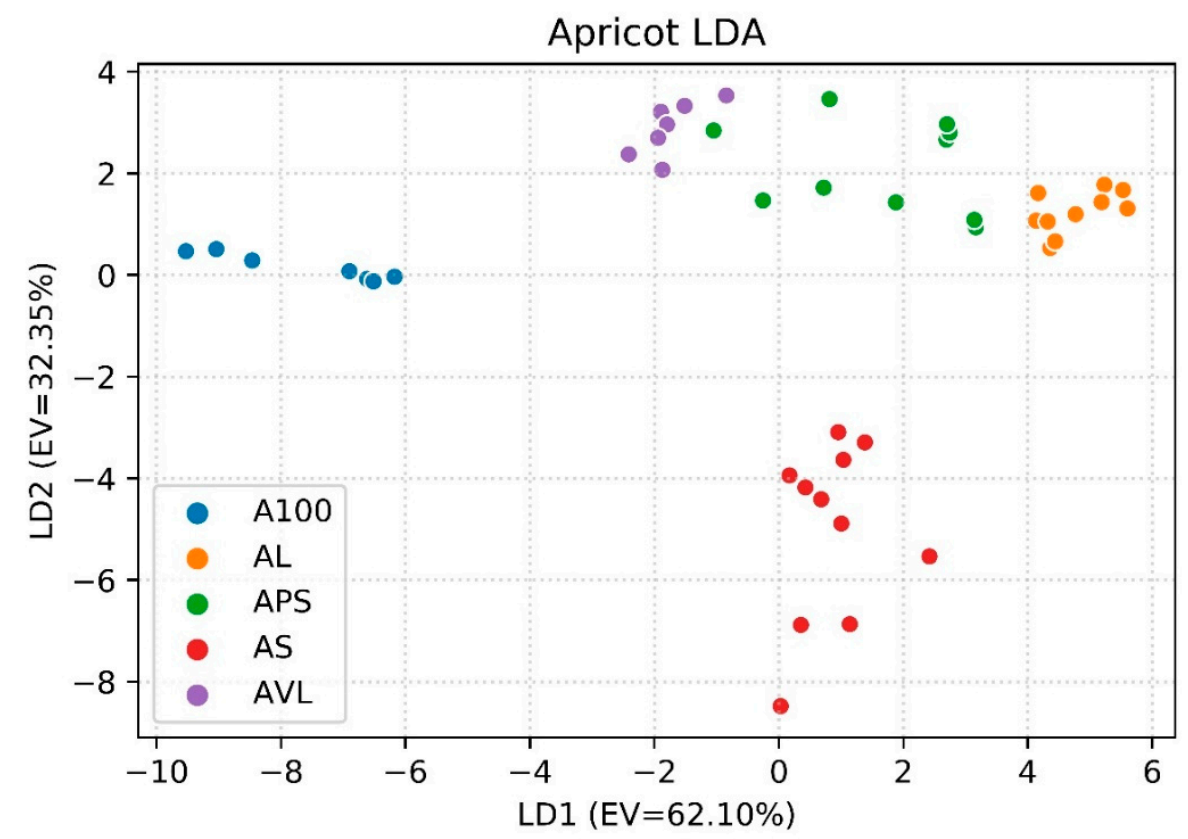

Figure 4. First two LD (linear discriminant) components for discrimination between the recipes of apricot jam (explained variance $(E V)=94.45 \%$ ); LDA: linear discriminant analysis; A100, AL, APS, AS, AVL: sample code.

Figure 5 shows the same typology of graph for cherry samples $(E V=99.18 \%)$. Unlike what is shown in Figure 4, C100 and CVL clusters overlap; in this case, the array seems to not be able to recognize that those samples come from different recipes. The CL and CS groups are very close on the graph. For cherry samples, the relative abundance of common compounds is $4.12 \%$ for CPS, $43.79 \%$ and $53.32 \%$ for C100 and CVL respectively, and $80 \%$ and $85.28 \%$ for CL and CS, respectively. These values reflect how the different recipes cluster in the LDA graph, and the relative abundance of common compounds can explain this result in this case. Furthermore, CPS is the only recipe that 
contains D-limonene-the abundance of which is 43 times higher than the second most abundant compound of the recipe in terms of the area of the peak and has lower quantities of furfural $(0.59 \%)$ and benzaldehyde (1.07\%). Indeed, the C100 and CVL recipes have an amount of furfural equal to $16.2 \%$ and $28 \%$ and of benzaldehyde equal to $5.47 \%$ and $11.7 \%$ respectively. However, for the CL and CS samples, benzaldehyde (58.65\% and $59.5 \%$ ) is much more present than furfural (18.24\% and $8.42 \%)$. In this case, LDA achieves a classification rate equal to $83.78 \%$. This result is lower than the previous due to the overlap of C100 and CVL clusters and to the fact that CL and CS are not $100 \%$ linearly separable.

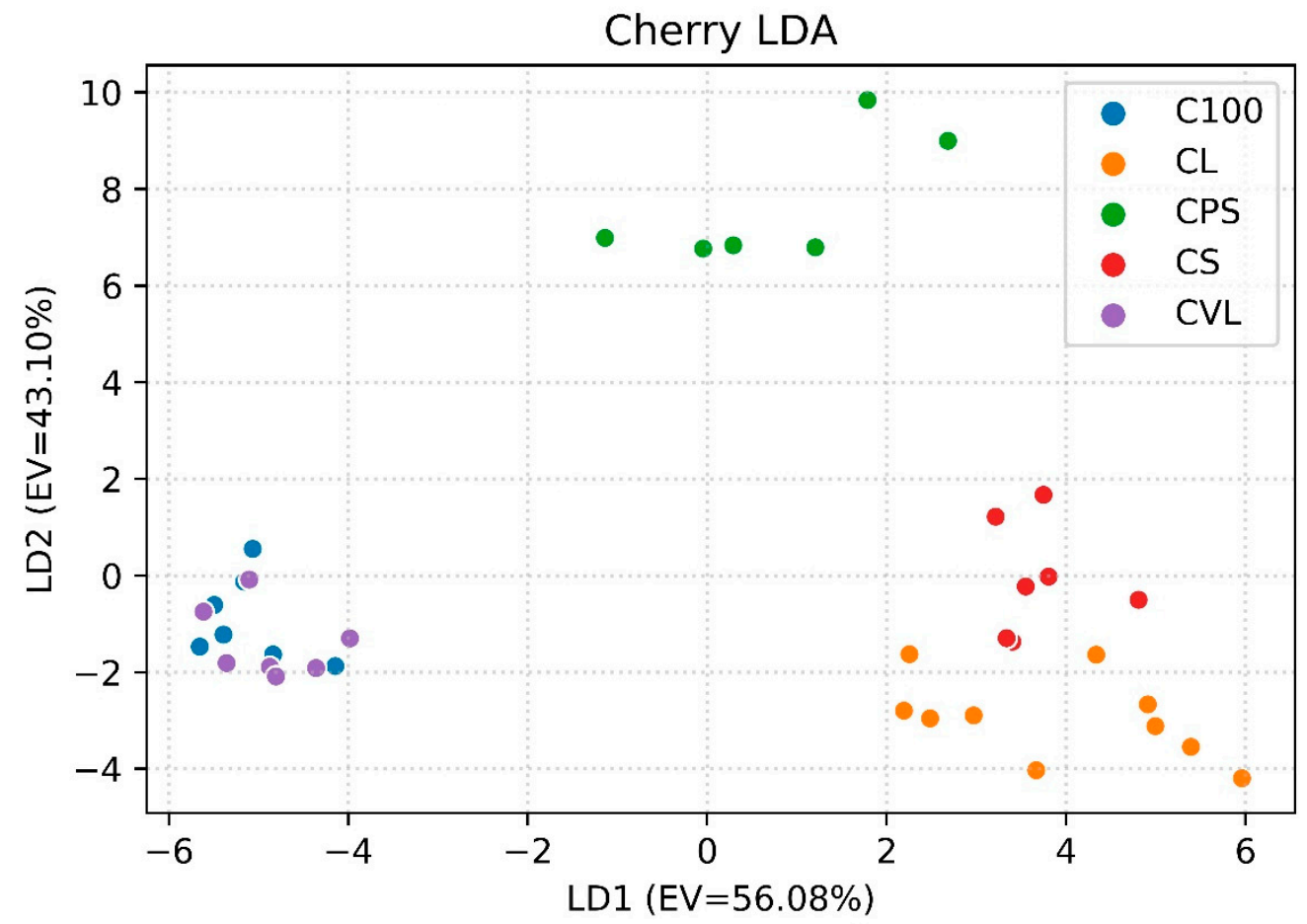

Figure 5. First two LD components for discrimination between the recipes of cherry jam $(\mathrm{EV}=99.18 \%)$.

Finally, in Figure 6, the LDAs for strawberry specimens are presented in the same way as for the previous fruits $(\mathrm{EV}=95.82 \%)$. S100 and SVL are the closest groups-a result that can be compared to the one obtained with cherry. On the contrary, there is better distinction between SS and SL in respect to CS and CL. In addition to the apricot samples, strawberry specimens show similar values of the abundance of common VOCs; these percentages range from $54.12 \%$ to $75.01 \%$. However, there are some differences if the most abundant compounds for each recipe are compared. The distance of the SS cluster from the others can be explained by the presence of acetone (relative abundance of $10.38 \%$, which is absent in the remaining recipes), ethyl acetate ( $4.58 \%$; it is present only in SL for a quantity equal to $2.48 \%$ ) and benzoic acid (3.83\%, in comparison to $0.35 \%-0.80 \%$ in the other samples) among the most abundant compounds. S100 and SVL have almost the same most abundant compounds (furfural, benzaldehyde, $\alpha$-terpineol, 1,6-octadien-3-ol, 3,7-dimethyl-, ammonium acetate and pentanal), except for the presence of cyclobutane, 1,2-bis(1-methylethenyl)-, trans- (10.87\% of relative abundance) and dimethyl sulfide $(6,20 \%)$ in S100 and nerolidyl acetate $(12.46 \%)$ in SVL. The same common VOCs can be found in SPS and SL (sample code); in this case, sensors recognition of the recipe could be addressed to 2-Heptenal, (Z)- (SPS: 3,6\%; SL: not present), Acetophenone (SPS: 3,39\%; SL: 1.49\%), Butanoic acid, 2-methyl- (SPS: 1,52\%; SL: 2.67\%) and Ethanone, 1-(2-furanyl)- (SPS: 1.53\%; SL: 2.48\%). Nevertheless, LDA accuracy is higher among the three recipes and it is equal to $97.06 \%$. 


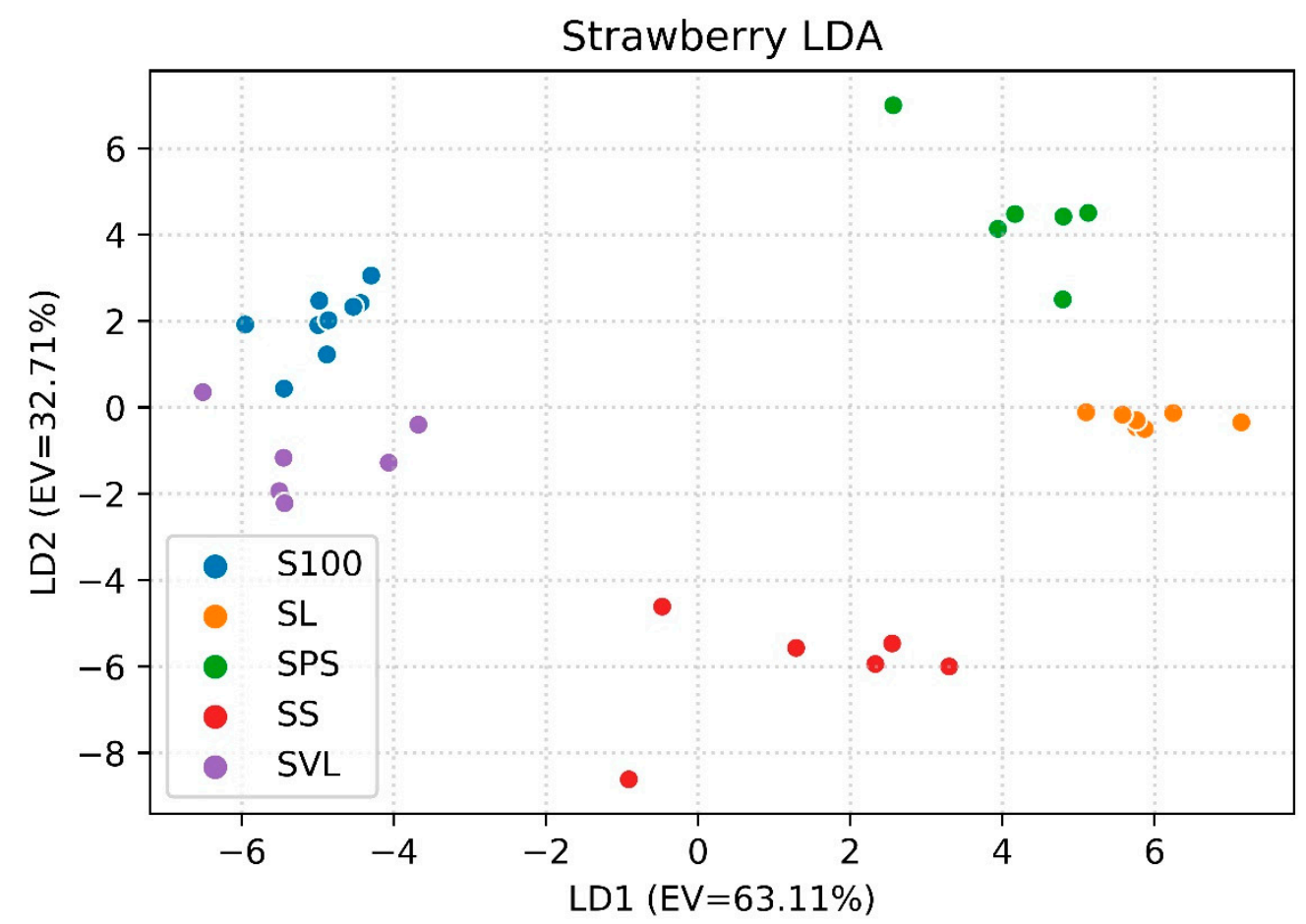

Figure 6. First two LD components for discrimination between the recipes of strawberry jam $(\mathrm{EV}=$ $95.82 \%)$.

\section{Conclusions}

This study aimed to characterize the aromatic fingerprint of fruit jams, taking into account three flavors and five recipes for a total of 15 different samples. The sets of VOCs provided by the GC-MS analysis showed that each specimen has a unique aroma, although there are common compounds among the recipes for each fruit. As derived from literature, those VOCs come from the common base that is the fruit itself. Hence, it is possible to assert that the thermal processes necessary for jam production do not alter the content of the used fruit. It is interesting to notice that all the samples have a small set of VOCs that has always been detected in this study: furfural; benzaldehyde; 1,6-Octadien-3-ol, 3,7-dimethyl-; L- $\alpha$-Terpineol; benzoic acid.

Furthermore, the innovative and real-time method developed for this study using the S3 device has excellent characteristics to be used in the production of this type of food product. In fact, once trained, S3 manages to highlight the real product differences and to provide a data item in a few minutes. Hence, the system provides an important information to promote and increase the guarantee of high standards of natural products. The impact of the work in this subject will be remarkable due to the lack of a reported bibliography. This work will pave the way to new studies that will deal with complex matrices as fruit jams and marmalades.

Author Contributions: Conceptualization, E.N.-C., M.A. and V.S.; methodology, E.N.C., M.A. and V.S.; software, E.N.-C., M.A., and V.S.; validation, E.C., G.S. and P.P.; formal analysis, E.N.-C., M.A., V.S. and P.P.; investigation, E.N.-C., M.A., V.S. and P.P.; resources, I.Z., A.T., P.P., E.C. and G.S.; data curation, M.A., E.N.-C. and V.S.; writing-original draft preparation, E.N.-C., M.A. and V.S.; writing-review and editing, E.C., V.S., G.S. and I.Z.; visualization, E.N.-C., M.A., V.S., I.Z., A.T., P.P., E.C. and G.S.; supervision, E.C., A.T. and G.S.

Funding: This research received no external funding.

Conflicts of Interest: The authors declare no conflict of interest. 


\section{Appendix A}

Table A1. APS sample VOCs.

\begin{tabular}{|c|c|c|}
\hline Retention Time & Name & Mean \\
\hline 1.655 & 1-Alanine ethylamide, (S)- & $1.72 \times 10^{5}$ \\
\hline 2.363 & Acetone & $8.67 \times 10^{4}$ \\
\hline 2.980 & 1,3-Propanediol, diacetate & $1.25 \times 10^{6}$ \\
\hline 4.136 & Pentanal & $4.27 \times 10^{6}$ \\
\hline 6.103 & Hexanal & $2.53 \times 10^{5}$ \\
\hline 6.707 & 2H-Pyran, 2-ethenyltetrahydro-2,6,6-trimethyl- & $1.21 \times 10^{6}$ \\
\hline 9.000 & Cyclohexene, 1-methyl-5-(1-methylethenyl)-, (R)- & $2.22 \times 10^{5}$ \\
\hline 9.150 & Eucalyptol & $1.76 \times 10^{5}$ \\
\hline 9.455 & 4-Ethylbenzoic acid, 1-(cyclopentyl)ethyl ester & $1.68 \times 10^{5}$ \\
\hline 10.310 & 5-Decen-1-ol, (E)- & $4.43 \times 10^{5}$ \\
\hline 10.502 & 1-Pentanol & $4.96 \times 10^{5}$ \\
\hline 11.248 & $(+)$-4-Carene & $2.92 \times 10^{5}$ \\
\hline 11.319 & Acetoin & $1.97 \times 10^{5}$ \\
\hline 11.717 & 1-Butanol, 2-methyl-, acetate & $3.27 \times 10^{5}$ \\
\hline 11.786 & Hexane, 3-ethyl- & $6.91 \times 10^{4}$ \\
\hline 11.964 & Cyclohexanone, 2,2,6-trimethyl- & $5.02 \times 10^{5}$ \\
\hline 12.200 & 2-Buten-1-ol, 3-methyl- & $4.76 \times 10^{5}$ \\
\hline 12.305 & 2,5-Octanedione & $3.58 \times 10^{5}$ \\
\hline 12.523 & 5-Hepten-2-one, 6-methyl- & $1.37 \times 10^{6}$ \\
\hline 13.261 & Cyclopropane, trimethyl(2-methyl-1-propenylidene)- & $5.67 \times 10^{4}$ \\
\hline 13.682 & Nonanal & $1.62 \times 10^{5}$ \\
\hline 13.748 & 1H-Pyrazole, 4,5-dihydro-5,5-dimethyl-4-isopropylidene- & $4.91 \times 10^{5}$ \\
\hline 13.885 & Propanenitrile, 3-(1-methylethoxy)- & $1.02 \times 10^{5}$ \\
\hline 14.000 & Ethane, 1,2-bis[(4-amino-3-furazanyl)oxy]- & $1.34 \times 10^{5}$ \\
\hline 14.148 & Benzene, 1-cyclopropylmethyl-4-(1-methylethyl)- & $1.08 \times 10^{5}$ \\
\hline 14.194 & Benzene, 1-cyclohexyl-3-methyl- & $4.04 \times 10^{4}$ \\
\hline 14.255 & 2-Octenal, (E)- & $1.75 \times 10^{5}$ \\
\hline 14.465 & $\alpha$-Methyl- $\alpha$-[4-methyl-3-pentenyl]oxiranemethanol & $1.55 \times 10^{6}$ \\
\hline 14.527 & Ethyl 2-(5-methyl-5-vinyltetrahydrofuran-2-yl)propan-2-yl carbonate & $5.00 \times 10^{5}$ \\
\hline 14.689 & Acetic acid & $6.19 \times 10^{6}$ \\
\hline 14.931 & Furfural & $3.52 \times 10^{7}$ \\
\hline 15.244 & 1-Hexanol, 2-ethyl- & $2.50 \times 10^{5}$ \\
\hline 15.573 & Ethanone, 1-(2-furanyl)- & $1.72 \times 10^{6}$ \\
\hline 15.881 & Benzaldehyde & $3.08 \times 10^{6}$ \\
\hline 16.143 & 1,6-Octadien-3-ol, 3,7-dimethyl- & $3.03 \times 10^{7}$ \\
\hline 16.286 & Naphthalene, 1,2,3,4-tetrahydro-1,1,6-trimethyl- & $6.42 \times 10^{5}$ \\
\hline 16.605 & 2-Furancarboxaldehyde, 5-methyl- & $8.24 \times 10^{5}$ \\
\hline 16.838 & Bicyclo[6.1.0]nonane, 9,9-dichloro- & $1.24 \times 10^{5}$ \\
\hline 16.974 & 3-Cyclohexen-1-ol, 4-methyl-1-(1-methylethyl)-, (R)- & $6.27 \times 10^{5}$ \\
\hline 17.049 & 5,7-Octadien-2-ol, 2,6-dimethyl- & $5.47 \times 10^{5}$ \\
\hline 17.272 & 1-Cyclohexene-1-carboxaldehyde, 2,6,6-trimethyl- & $1.44 \times 10^{6}$ \\
\hline 17.441 & 2(5H)-Furanone, 4,5,5-trimethyl-3-(3-methyl-2-methylenebutyl)- & $2.03 \times 10^{6}$ \\
\hline 17.502 & 1-methyl-4-(prop-1-en-2-yl)-7-oxabicyclo[4.1.0]heptan-2one & $4.42 \times 10^{5}$ \\
\hline 17.770 & 2-Furanmethanol & $5.34 \times 10^{5}$ \\
\hline 17.896 & Butanoic acid, 2-methyl- & $1.80 \times 10^{6}$ \\
\hline 18.247 & L- $\alpha$-Terpineol & $1.76 \times 10^{7}$ \\
\hline 18.383 & Hexanoic acid, anhydride & $8.31 \times 10^{5}$ \\
\hline 18.789 & 2,6-Octadiene, 1-(1-ethoxyethoxy)-3,7-dimethyl- & $2.59 \times 10^{5}$ \\
\hline 18.968 & 1, 1, 5-Trimethyl-1, 2-dihydronaphthalene & $1.14 \times 10^{6}$ \\
\hline 19.276 & Dodecanedioic acid, bis(tert-butyldimethylsilyl) ester & $5.03 \times 10^{4}$ \\
\hline
\end{tabular}


Table A1. Cont.

\begin{tabular}{ccc}
\hline Retention Time & Name & Mean \\
\hline 20.067 & Cyclopentaneundecanoic acid & $2.80 \times 10^{6}$ \\
20.226 & 5,9-Undecadien-2-one, 6,10-dimethyl-, (Z)- & $8.05 \times 10^{5}$ \\
20.366 & 7-Octen-3-ol, 2,3,6-trimethyl- & $5.37 \times 10^{4}$ \\
20.504 & Benzyl alcohol & $3.60 \times 10^{5}$ \\
20.703 & 4-Acetyl-1-methylcyclohexene & $2.59 \times 10^{5}$ \\
20.911 & Phenylethyl Alcohol & $3.78 \times 10^{5}$ \\
21.252 & trans- $\beta$-Ionone & $9.88 \times 10^{5}$ \\
21.433 & Bromoacetic acid, dodecyl ester & $3.20 \times 10^{5}$ \\
21.790 & C-Hexen-1-ol, 6-(2,6,6-trimethyl-1-cyclohexenyl)-4-methyl-, (E)- & $1.93 \times 10^{5}$ \\
21.956 & Carbamic acid, phenyl ester & $1.90 \times 10^{5}$ \\
22.244 & Nerolidyl acetate & $1.32 \times 10^{6}$ \\
22.300 & Octanoic acid & $1.34 \times 10^{5}$ \\
22.461 & 1,6,10-Dodecatrien-3-ol,3,7,11-trimethyl-, [S-(Z)]- & $2.22 \times 10^{5}$ \\
23.517 & 2(3H)-Furanone, 5-hexyldihydro- & $7.04 \times 10^{5}$ \\
25.625 & gamma.-Dodecalactone & $4.59 \times 10^{5}$ \\
25.780 & Benzoic acid & $5.03 \times 10^{4}$ \\
26.326 & Tridecanoic acid & $4.44 \times 10^{5}$ \\
26.615 & 5-Hydroxymethylfurfural & $6.65 \times 10^{4}$ \\
26.890 & 2-tert-Butyl-4-hexylphenol & $1.52 \times 10^{5}$ \\
26.973 & 2(4H)-Benzofuranone, 5,6,7,7a-tetrahydro-4, & $4.69 \times 10^{4}$ \\
27.331 & di(Butoxyethyl)adipate & $2.48 \times 10^{5}$ \\
27.729 & Phosphine, 1,3-propanediylbis[bis(1-methylethyl)- & $2.41 \times 10^{5}$ \\
28.857 & 1,2-Benzenedicarboxylic acid, bis(2-methylpropyl) ester & $6.88 \times 10^{4}$ \\
\hline
\end{tabular}

Table A2. AVL sample VOCs.

\begin{tabular}{ccc}
\hline Retention Time & Name & Mean \\
\hline 2.390 & 2-Hexanone, 4-hydroxy-5-methyl-3-propyl- & $2.07 \times 10^{5}$ \\
6.146 & Hexanal & $1.99 \times 10^{6}$ \\
6.703 & 2H-Pyran, 2-ethenyltetrahydro-2,6,6-trimethyl- & $9.72 \times 10^{5}$ \\
10.333 & 9-Dodecen-1-ol, acetate, (Z)- & $3.72 \times 10^{5}$ \\
11.344 & Acetoin & $3.12 \times 10^{5}$ \\
11.990 & Cyclohexanone, 2,2,6-trimethyl- & $4.54 \times 10^{5}$ \\
12.214 & 2-Heptenal, (Z)- & $4.12 \times 10^{5}$ \\
12.544 & 5-Hepten-2-one, 6-methyl- & $1.69 \times 10^{6}$ \\
13.644 & Nonanal & $3.00 \times 10^{5}$ \\
13.769 & 1,3-Hexadiene, 3-ethyl-2-methyl- & $9.69 \times 10^{5}$ \\
14.037 & 2-Octenal, (E)- & $3.06 \times 10^{5}$ \\
14.279 & 1H-Pyrazole, 4,5-dihydro-5,5-dimethyl-4-isopropylidene- & $3.51 \times 10^{5}$ \\
14.485 & Acetic acid & $2.01 \times 10^{6}$ \\
14.711 & Furfural & $5.22 \times 10^{6}$ \\
14.951 & 1-Hexanol, 2-ethyl- & $1.46 \times 10^{7}$ \\
15.264 & 2,4-Heptadienal, (E,E)- & $2.11 \times 10^{5}$ \\
15.378 & Benzaldehyde & $1.14 \times 10^{5}$ \\
15.903 & 1,6-Octadien-3-ol,3,7-dimethyl- & $2.64 \times 10^{6}$ \\
16.160 & 2-M-methyl-3-pentenyl]oxiranemethanol & $2.66 \times 10^{7}$ \\
16.365 & 2-Furancarboxaldehyde, 5-methyl- & $3.91 \times 10^{5}$ \\
16.630 & 3-Buten-2-ol, 4-(2,6,6-trimethyl-1-cyclohexen-1-yl)- & $2.51 \times 10^{5}$ \\
16.766 & 3-Cyclohexen-1-ol, 4-methyl-1-(1-methylethyl)-, (R)- & $1.80 \times 10^{5}$ \\
16.994 & Naphexene-1-carboxaldehyde, 2,6,6-trimethyl- & $1.13 \times 10^{6}$ \\
17.292 & & $1.82 \times 10^{6}$ \\
\hline
\end{tabular}


Table A2. Cont.

\begin{tabular}{|c|c|c|}
\hline Retention Time & Name & Mean \\
\hline 17.461 & 1-methyl-4-(prop-1-en-2-yl)-7-oxabicyclo[4.1.0]heptan-2one & $1.11 \times 10^{6}$ \\
\hline 17.913 & Butanoic acid, 2-methyl- & $9.28 \times 10^{5}$ \\
\hline 18.266 & L- $\alpha$-Terpineol & $1.97 \times 10^{7}$ \\
\hline 19.006 & 1, 1, 5-Trimethyl-1, 2-dihydronaphthalene & $7.98 \times 10^{5}$ \\
\hline 19.754 & Bicyclo[3.1.0]hexane-6-methanol, 2-hydroxy-1,4,4-trimethyl- & $1.25 \times 10^{5}$ \\
\hline 20.088 & Cyclopentaneundecanoic acid & $2.59 \times 10^{6}$ \\
\hline 20.245 & 5,9-Undecadien-2-one, 6,10-dimethyl-, (Z)- & $1.11 \times 10^{6}$ \\
\hline 20.523 & Benzyl alcohol & $4.97 \times 10^{5}$ \\
\hline 20.719 & 4-Acetyl-1-methylcyclohexene & $3.23 \times 10^{5}$ \\
\hline 20.933 & Phenylethyl Alcohol & $2.65 \times 10^{5}$ \\
\hline 21.276 & trans- $\beta$-Ionone & $1.26 \times 10^{6}$ \\
\hline 21.990 & 4-(2,4,4-Trimethyl-cyclohexa-1,5-dienyl)-but-3-en-2-one & $1.69 \times 10^{5}$ \\
\hline 22.262 & 1,6,10-Dodecatrien-3-ol, 3,7,11-trimethyl-, [S-(Z)]- & $1.92 \times 10^{5}$ \\
\hline 22.482 & Octanoic acid & $1.83 \times 10^{5}$ \\
\hline 23.537 & 2(3H)-Furanone, 5-hexyldihydro- & $4.82 \times 10^{5}$ \\
\hline 25.648 & 2(4H)-Benzofuranone, 5,6,7,7a-tetrahydro-4,4,7a-trimethyl- & $6.93 \times 10^{5}$ \\
\hline 26.342 & Benzoic acid & $7.11 \times 10^{5}$ \\
\hline 26.630 & Tridecanoic acid & $1.04 \times 10^{5}$ \\
\hline
\end{tabular}

Table A3. A100 sample VOCs.

\begin{tabular}{|c|c|c|}
\hline Retention Time & Name & Mean \\
\hline 4.129 & Pentanal & $4.47 \times 10^{6}$ \\
\hline 6.164 & Hexanal & $8.99 \times 10^{5}$ \\
\hline 6.723 & 2H-Pyran, 2-ethenyltetrahydro-2,6,6-trimethyl- & $5.27 \times 10^{6}$ \\
\hline 9.027 & Cyclobutane, 1,2-bis(1-methylethenyl)-, trans- & $3.34 \times 10^{6}$ \\
\hline 9.452 & Z-7-Decen-1-yl acetate & $1.68 \times 10^{6}$ \\
\hline 10.333 & Bicyclo[3.1.0]hexane-6-methanol, 2-hydroxy-1,4,4-trimethyl- & $2.46 \times 10^{6}$ \\
\hline 11.274 & $(+)-4$-Carene & $1.05 \times 10^{6}$ \\
\hline 11.729 & 2-Propanone, 1-hydroxy- & $5.09 \times 10^{5}$ \\
\hline 11.995 & Cyclohexanone, 2,2,6-trimethyl- & $8.28 \times 10^{5}$ \\
\hline 12.325 & 2,5-Octanedione & $5.20 \times 10^{5}$ \\
\hline 12.554 & 5-Hepten-2-one, 6-methyl- & $2.13 \times 10^{6}$ \\
\hline 13.284 & 1,5,5-Trimethyl-6-methylene-cyclohexene & $3.09 \times 10^{5}$ \\
\hline 13.654 & Nonanal & $5.36 \times 10^{5}$ \\
\hline 13.775 & Isophorone & $7.89 \times 10^{5}$ \\
\hline 14.169 & (1,4-Dimethylpent-2-enyl)benzene & $1.53 \times 10^{6}$ \\
\hline 14.494 & Ethyl 2-(5-methyl-5-vinyltetrahydrofuran-2-yl)propan-2-yl carbonate & $5.08 \times 10^{6}$ \\
\hline 14.712 & Acetic acid & $4.14 \times 10^{6}$ \\
\hline 14.958 & Furfural & $5.87 \times 10^{7}$ \\
\hline 15.273 & 1-Hexanol, 2-ethyl- & $1.43 \times 10^{6}$ \\
\hline 15.602 & Ethanone, 1-(2-furanyl)- & $2.85 \times 10^{6}$ \\
\hline 15.853 & Benzaldehyde & $5.58 \times 10^{6}$ \\
\hline 16.169 & 1,6-Octadien-3-ol, 3,7-dimethyl- & $3.27 \times 10^{7}$ \\
\hline 16.326 & Naphthalene, 1,2,3,4-tetrahydro-1,1,6-trimethyl- & $4.60 \times 10^{6}$ \\
\hline 16.644 & 2-Furancarboxaldehyde, 5-methyl- & $1.56 \times 10^{6}$ \\
\hline 16.732 & Megastigma-4,6(E),8(Z)-triene & $5.55 \times 10^{5}$ \\
\hline 16.999 & 3-Cyclohexen-1-ol, 4-methyl-1-(1-methylethyl)-, (R)- & $1.35 \times 10^{6}$ \\
\hline
\end{tabular}


Table A3. Cont.

\begin{tabular}{ccc}
\hline Retention Time & Name & Mean \\
\hline 17.075 & 7-Octen-2-ol, 2-methyl-6-methylene- & $1.31 \times 10^{6}$ \\
17.303 & 3-Buten-2-one, & $5.52 \times 10^{6}$ \\
17.474 & 1-Cyclohexene-1-carboxaldehyde, 2,6-trimethyl- & $2.22 \times 10^{6}$ \\
17.791 & 3-methyl-4-(1,3,3-trimethyl-7-oxabicyclo[4.1.0]heptan-1-yl)- & $6.00 \times 10^{5}$ \\
17.968 & 2-Furanmethanol & $1.47 \times 10^{6}$ \\
18.014 & Benzene, 1,2,3,4-tetramethyl-4-(1-methylethenyl)- & $3.94 \times 10^{7}$ \\
18.791 & L- $\alpha$-Terpineol & $2.13 \times 10^{5}$ \\
18.999 & Dodecanedioic acid, bis(tert-butyldimethylsilyl) ester & $3.89 \times 10^{6}$ \\
20.095 & 1, 1,5-Trimethyl-1, 2-dihydronaphthalene & $2.88 \times 10^{6}$ \\
20.257 & Geraniol & $7.75 \times 10^{5}$ \\
20.526 & 5,9-Undecadien-2-one, 6,10-dimethyl-, (Z)- & $7.88 \times 10^{5}$ \\
20.731 & 2-Caren-10-al & $7.88 \times 10^{5}$ \\
20.942 & 4-Acetyl-1-methylcyclohexene & $5.97 \times 10^{5}$ \\
21.285 & Phenylethyl Alcohol & $1.44 \times 10^{6}$ \\
21.808 & trans- $\beta$-Ionone & $6.02 \times 10^{5}$ \\
23.545 & Calarene epoxide & $7.06 \times 10^{5}$ \\
26.346 & 2(3H)-Furanone, 5-hexyldihydro- & $9.42 \times 10^{5}$ \\
\hline
\end{tabular}

Table A4. AL sample VOCs.

\begin{tabular}{ccc}
\hline Retention Time & Name & Mean \\
\hline 2.389 & Acetone & $5.95 \times 10^{5}$ \\
2.978 & Ethyl Acetate & $2.50 \times 10^{6}$ \\
4.160 & Pentanal & $8.99 \times 10^{5}$ \\
6.176 & Hexanal & $8.03 \times 10^{5}$ \\
6.775 & 2H-Pyran, 2-ethenyltetrahydro-2,6,6-trimethyl- & $7.54 \times 10^{5}$ \\
9.439 & 1-Butanol, 3-methyl- & $4.50 \times 10^{5}$ \\
10.384 & 3-Tridecene & $3.94 \times 10^{5}$ \\
11.780 & 5,9-Dodecadien-2-one, 6,10-dimethyl-, (E,E))- & $2.58 \times 10^{5}$ \\
12.052 & Cyclohexanone, 2,2,6-trimethyl- & $4.63 \times 10^{5}$ \\
12.267 & 2-Heptenal, (Z)- & $3.15 \times 10^{5}$ \\
12.377 & 2,5-Hexanedione & $2.04 \times 10^{5}$ \\
12.599 & 5-Hepten-2-one, 6-methyl- & $1.25 \times 10^{6}$ \\
13.816 & Isophorone & $6.51 \times 10^{5}$ \\
14.092 & 1,3-Hexadiene, 3-ethyl-2-methyl- & $1.77 \times 10^{5}$ \\
14.324 & 2-Octenal, (E)- & $9.62 \times 10^{4}$ \\
14.529 & Ethyl 2-(5-methyl-5-vinyltetrahydrofuran-2-yl)propan-2-yl carbonate & $1.35 \times 10^{6}$ \\
14.773 & Acetic acid & $3.04 \times 10^{6}$ \\
14.999 & Furfural & $2.40 \times 10^{7}$ \\
15.644 & Ethanone, 1-(2-furanyl)- & $1.31 \times 10^{6}$ \\
15.947 & Benzaldehyde & $3.03 \times 10^{6}$ \\
16.201 & 2-Dodecenoic acid & $3.80 \times 10^{6}$ \\
16.346 & 2-Furanmethanol & $9.07 \times 10^{5}$ \\
16.685 & 1,6-Octadien-3-ol, 3,7-dimethyl- & $5.97 \times 10^{5}$ \\
17.051 & Nonanoic acid, hexyl ester & $6.28 \times 10^{5}$ \\
17.334 & 2-Furancarboxaldehyde, 5-methyl- & $1.44 \times 10^{6}$ \\
17.513 & 3-Cyclohexen-1-ol, 4-methyl-1-(1-methylethyl)-, (R)- & $3.84 \times 10^{5}$ \\
17.837 & 1-Cychexene-1-carboxaldehyde, 2,6,6-trimethyl- & $3.15 \times 10^{5}$ \\
\hline & 2- &
\end{tabular}


Table A4. Cont.

\begin{tabular}{|c|c|c|}
\hline Retention Time & Name & Mean \\
\hline 17.972 & Methyl 4-hydroxybutanoate & $7.85 \times 10^{5}$ \\
\hline 18.311 & L- $\alpha$-Terpineol & $4.16 \times 10^{6}$ \\
\hline 18.495 & Heptanoic acid, 2-(acetyloxy)-, methyl ester & $3.10 \times 10^{5}$ \\
\hline 19.036 & Oxime-, methoxy-phenyl-_ & $8.00 \times 10^{5}$ \\
\hline 20.140 & Heptanoic acid & $1.15 \times 10^{6}$ \\
\hline 20.285 & 5,9-Undecadien-2-one, 6,10-dimethyl-, (Z)- & $5.00 \times 10^{5}$ \\
\hline 20.568 & Benzyl alcohol & $3.02 \times 10^{5}$ \\
\hline 20.766 & 4-Acetyl-1-methylcyclohexene & $1.18 \times 10^{5}$ \\
\hline 20.970 & Butylated Hydroxytoluene & $3.31 \times 10^{5}$ \\
\hline 21.315 & trans- $\beta$-Ionone & $8.17 \times 10^{5}$ \\
\hline 21.499 & 1-Dodecanol & $2.48 \times 10^{5}$ \\
\hline 21.815 & Orcinol & $9.89 \times 10^{4}$ \\
\hline 22.305 & 1,6,10-Dodecatrien-3-ol, 3,7,11-trimethyl-, [S-(Z)]- & $1.76 \times 10^{5}$ \\
\hline 22.533 & Octanoic acid & $2.29 \times 10^{5}$ \\
\hline 23.644 & Tridecanoic acid & $3.83 \times 10^{5}$ \\
\hline 24.685 & n-Decanoic acid & $1.09 \times 10^{5}$ \\
\hline 25.712 & 2(4H)-Benzofuranone, 5,6,7,7a-tetrahydro-4,4,7a-trimethyl- & $3.01 \times 10^{5}$ \\
\hline 26.432 & Benzoic acid & $2.70 \times 10^{5}$ \\
\hline 26.555 & 5H-1-Pyrindine & $5.57 \times 10^{5}$ \\
\hline 26.691 & Dodecanoic acid & $1.15 \times 10^{5}$ \\
\hline 26.980 & 5-Hydroxymethylfurfural & $2.12 \times 10^{5}$ \\
\hline 27.813 & Decanoic acid, decyl ester & $3.59 \times 10^{5}$ \\
\hline
\end{tabular}

Table A5. AS sample VOCs.

\begin{tabular}{ccc}
\hline Retention Time & Name & Mean \\
\hline 2.394 & Acetone & $4.03 \times 10^{6}$ \\
3.110 & Ethyl Acetate & $3.14 \times 10^{6}$ \\
4.127 & Pentanal & $2.52 \times 10^{6}$ \\
6.126 & Hexanal & $2.12 \times 10^{6}$ \\
6.684 & 2H-Pyran, 2-ethenyltetrahydro-2,6,6-trimethyl- & $1.56 \times 10^{6}$ \\
9.437 & 3-Dodecyne & $7.22 \times 10^{5}$ \\
10.308 & 3-Tridecene & $8.45 \times 10^{5}$ \\
11.327 & Acetoin & $2.37 \times 10^{5}$ \\
11.708 & 1-Butanol, 2-methyl-, acetate & $5.35 \times 10^{5}$ \\
11.976 & Cyclohexanone, 2,2,6-trimethyl- & $9.01 \times 10^{5}$ \\
12.200 & 2-Heptenal, (Z)- & $7.19 \times 10^{5}$ \\
12.524 & 5-Hepten-2-one, 6-methyl- & $1.84 \times 10^{6}$ \\
13.633 & Nonanal & $2.16 \times 10^{5}$ \\
13.755 & 4,5-dihydro-5,5-dimethyl-4-isopropylidene- & $1.11 \times 10^{6}$ \\
14.023 & 1,3-Hexadiene, 3-ethyl-2-methyl- & $3.06 \times 10^{5}$ \\
14.142 & (1,4-Dimethylpent-2-enyl)benzene & $2.37 \times 10^{5}$ \\
14.267 & 2-Octenal, (E)- & $3.15 \times 10^{5}$ \\
14.349 & 3-Furaldehyde & $4.23 \times 10^{5}$ \\
14.469 & 1H-Pyrazole & $3.01 \times 10^{6}$ \\
14.671 & (1,6-Octadien-3-ol, 3,7-dimethyl- & $9.60 \times 10^{6}$ \\
14.932 & E-Methyl- $\alpha$-[4-methyl-3-pentenyl]oxiranemethanol & $4.37 \times 10^{7}$ \\
15.365 & Ammonium acetate & $1.60 \times 10^{5}$ \\
15.578 & Furfural & $2.67 \times 10^{6}$ \\
15.876 & 2,4-Heptadienal, (E,E)- & $7.65 \times 10^{6}$ \\
16.143 & Ethanone, 1-(2-furanyl)- & $4.83 \times 10^{6}$ \\
\hline
\end{tabular}


Table A5. Cont.

\begin{tabular}{|c|c|c|}
\hline Retention Time & Name & Mean \\
\hline 16.303 & Naphthalene, 1,2,3,4-tetrahydro-1,1,6-trimethyl- & $9.30 \times 10^{5}$ \\
\hline 16.615 & 2-Furancarboxaldehyde, 5-methyl- & $1.42 \times 10^{6}$ \\
\hline 16.840 & $\begin{array}{l}\text { Furo[3,4-b]furan-2,6(3H,4H)-dione, 4-ethyldihydro-3-methylene-, } \\
\qquad[3 \mathrm{aR}-(3 \mathrm{a} \alpha, 4 \beta, 6 \mathrm{a} \alpha)]-\end{array}$ & $2.39 \times 10^{5}$ \\
\hline 16.976 & 3-Cyclohexen-1-ol, 4-methyl-1-(1-methylethyl)-, (R)- & $8.61 \times 10^{5}$ \\
\hline 17.276 & 3-Cyclohexene-1-carboxaldehyde, 1,3,4-trimethyl- & $1.85 \times 10^{6}$ \\
\hline 17.444 & $\begin{array}{l}\text { 3-Buten-2-one, } \\
\text { 3-methyl-4-(1,3,3-trimethyl-7-oxabicyclo[4.1.0]heptan-1-yl)- }\end{array}$ & $7.53 \times 10^{5}$ \\
\hline 17.760 & 2-Furanmethanol & $2.59 \times 10^{5}$ \\
\hline 17.884 & Butanoic acid, 2-methyl- & $2.79 \times 10^{6}$ \\
\hline 18.151 & Bicyclo[3.2.2]non-8-en-6-ol, (1R,5-cis,6-cis)- & $7.08 \times 10^{5}$ \\
\hline 18.249 & L- $\alpha$-Terpineol & $1.08 \times 10^{7}$ \\
\hline 18.839 & Propanedioic acid, propyl- & $5.68 \times 10^{5}$ \\
\hline 19.029 & Naphthalene, 1,2-dihydro-2,5,8-trimethyl- & $5.14 \times 10^{5}$ \\
\hline 19.275 & Dodecanedioic acid, bis(tert-butyldimethylsilyl) ester & $1.76 \times 10^{5}$ \\
\hline 19.950 & 4-Methylphenyl acetone & $1.61 \times 10^{5}$ \\
\hline 20.067 & Heptanoic acid & $8.70 \times 10^{5}$ \\
\hline 20.228 & 5,9-Undecadien-2-one, 6,10-dimethyl-, (E)- & $5.53 \times 10^{5}$ \\
\hline 20.500 & Benzyl alcohol & $6.87 \times 10^{5}$ \\
\hline 20.708 & 4-Acetyl-1-methylcyclohexene & $2.21 \times 10^{5}$ \\
\hline 20.926 & 3,5-Octadiene, 4,5-diethyl-, (E,Z)- & $2.10 \times 10^{5}$ \\
\hline 21.257 & trans- $\beta$-Ionone & $1.12 \times 10^{6}$ \\
\hline 21.466 & 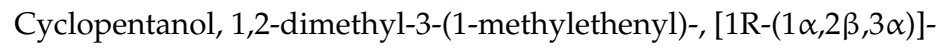 & $3.23 \times 10^{5}$ \\
\hline 21.746 & 2,5-Furandicarboxaldehyde & $2.24 \times 10^{5}$ \\
\hline 21.954 & Carbamic acid, N-(3-ethylphenyl)-, phenyl ester & $2.96 \times 10^{5}$ \\
\hline 22.076 & 3-Furancarboxylic acid, methyl ester & $3.27 \times 10^{5}$ \\
\hline 22.247 & 1,6,10-Dodecatrien-3-ol, 3,7,11-trimethyl- & $3.16 \times 10^{5}$ \\
\hline 22.455 & Octanoic acid & $2.15 \times 10^{5}$ \\
\hline 23.583 & 2(3H)-Furanone, 5-hexyldihydro- & $3.83 \times 10^{5}$ \\
\hline 24.988 & Phenol, 2,4-bis(1,1-dimethylethyl)- & $2.94 \times 10^{5}$ \\
\hline 25.624 & 2(4H)-Benzofuranone, 5,6,7,7a-tetrahydro-4,4,7a-trimethyl- & $4.65 \times 10^{5}$ \\
\hline 26.270 & Benzoic acid & $1.53 \times 10^{7}$ \\
\hline 26.889 & 5-Hydroxymethylfurfural & $6.05 \times 10^{5}$ \\
\hline 27.803 & 4a,8a-Butano[1,4]dioxino[2,3-b]-1,4-dioxin, tetrahydro- & $1.45 \times 10^{5}$ \\
\hline
\end{tabular}

Table A6. SPS sample VOCs.

\begin{tabular}{ccc}
\hline Retention Time & Name & Mean \\
\hline 1.835 & D-Alanine & $2.19 \times 10^{5}$ \\
2.118 & Dimethyl sulfide & $2.55 \times 10^{5}$ \\
4.207 & Pentanal & $9.61 \times 10^{6}$ \\
5.183 & Butanoic acid, ethyl ester & $9.08 \times 10^{5}$ \\
5.811 & 1-Penten-3-one, 2-methyl- & $1.53 \times 10^{6}$ \\
5.853 & Benzothiophene-3-carboxylic acid, & $7.09 \times 10^{4}$ \\
6.121 & 4,5,6,7-tetrahydro-6-tert-butyl-2-cyclopropanoylamino-, ethyl ester & $2.94 \times 10^{6}$ \\
7.200 & Hexanal & $5.80 \times 10^{5}$ \\
7.664 & 3-Penten-2-one, (E)- & $1.31 \times 10^{5}$ \\
10.180 & 3-Carene & $1.81 \times 10^{5}$ \\
10.560 & Hexanoic acid, ethyl ester & $5.81 \times 10^{5}$ \\
\hline
\end{tabular}


Table A6. Cont.

\begin{tabular}{|c|c|c|}
\hline Retention Time & Name & Mean \\
\hline 11.401 & Acetoin & $5.90 \times 10^{5}$ \\
\hline 11.449 & Octanal & $6.62 \times 10^{5}$ \\
\hline 11.791 & 1-Octen-3-one & $1.82 \times 10^{6}$ \\
\hline 12.261 & 2-Heptenal, (Z)- & $4.58 \times 10^{6}$ \\
\hline 12.365 & 5-Hepten-2-one, 6-methyl- & $2.30 \times 10^{6}$ \\
\hline 12.685 & 1-Hexanol & $1.76 \times 10^{5}$ \\
\hline 13.682 & Nonanal & $4.64 \times 10^{5}$ \\
\hline 13.888 & 2-Decen-1-ol, (E)- & $1.08 \times 10^{6}$ \\
\hline 14.020 & 1,3-Hexadiene, 3-ethyl-2-methyl- & $1.20 \times 10^{5}$ \\
\hline 14.322 & 2-Octenal, (E)- & $1.47 \times 10^{6}$ \\
\hline 14.522 & Ethyl 2-(5-methyl-5-vinyltetrahydrofuran-2-yl)propan-2-yl carbonate & $6.66 \times 10^{5}$ \\
\hline 14.756 & Ammonium acetate & $6.16 \times 10^{6}$ \\
\hline 14.992 & Furfural & $2.27 \times 10^{7}$ \\
\hline 15.303 & 1-Hexanol, 2-ethyl- & $1.46 \times 10^{5}$ \\
\hline 15.635 & Ethanone, 1-(2-furanyl)- & $1.94 \times 10^{6}$ \\
\hline 15.929 & Benzaldehyde & $4.65 \times 10^{6}$ \\
\hline 16.197 & 1,6-Octadien-3-ol, 3,7-dimethyl- & $1.50 \times 10^{7}$ \\
\hline 16.327 & 1-Octanol & $7.71 \times 10^{5}$ \\
\hline 16.929 & 3(2H)-Furanone, 4-methoxy-2,5-dimethyl- & $2.56 \times 10^{6}$ \\
\hline 17.095 & 2,4-Di-tert-butyl-6-(tert-butylamino)phenol & $4.56 \times 10^{4}$ \\
\hline 17.109 & trans-2-Undecen-1-ol & $9.08 \times 10^{4}$ \\
\hline 17.367 & Butanoic acid & $3.58 \times 10^{5}$ \\
\hline 17.500 & Butanoic acid, 4-hydroxy- & $7.04 \times 10^{5}$ \\
\hline 17.564 & 2-Decenal, $(\mathrm{E})$ - & $4.68 \times 10^{5}$ \\
\hline 17.770 & Acetophenone & $4.31 \times 10^{6}$ \\
\hline 17.892 & Butanoic acid, 2-methyl- & $1.94 \times 10^{6}$ \\
\hline 18.130 & $\beta$-d-Mannofuranoside, phenyl & $1.00 \times 10^{5}$ \\
\hline 18.138 & Octadecanoic acid, 4-methyl- & $6.77 \times 10^{4}$ \\
\hline 18.305 & L- $\alpha$-Terpineol & $4.53 \times 10^{6}$ \\
\hline 18.389 & 6,6,7-Trimethyl-octane-2,5-dione & $1.95 \times 10^{5}$ \\
\hline 18.415 & Hexanoic acid, anhydride & $5.08 \times 10^{5}$ \\
\hline 18.442 & n-Caproic acid vinyl ester & $2.52 \times 10^{5}$ \\
\hline 18.736 & 2,6-Octadienal, 3,7-dimethyl-, (E)- & $6.19 \times 10^{5}$ \\
\hline 18.981 & n-Octylsuccinic anhydride & $8.99 \times 10^{5}$ \\
\hline 19.035 & Oxime-, methoxy-phenyl-_ & $6.87 \times 10^{5}$ \\
\hline 19.228 & Pseduosarsasapogenin-5,20-dien methyl ether & $1.81 \times 10^{5}$ \\
\hline 19.276 & $5 \alpha$-Cholestan-2-one, oxime & $1.86 \times 10^{5}$ \\
\hline 19.487 & Bicyclo[2.2.1]heptan-2-one, 1-(bromomethyl)-7,7-dimethyl-, (1S)- & $3.88 \times 10^{6}$ \\
\hline 20.106 & Heptanoic acid & $2.58 \times 10^{6}$ \\
\hline 20.283 & 5,9-Undecadien-2-one, 6,10-dimethyl-, (Z)- & $7.55 \times 10^{5}$ \\
\hline 20.559 & Benzyl alcohol & $3.59 \times 10^{5}$ \\
\hline 20.971 & Phenylethyl Alcohol & $5.90 \times 10^{5}$ \\
\hline 21.277 & 2,3-Dehydro-4-oxo- $\beta$-ionol & $2.17 \times 10^{5}$ \\
\hline 21.322 & Stevioside & $1.33 \times 10^{5}$ \\
\hline 21.486 & 1-Dodecanol & $3.28 \times 10^{5}$ \\
\hline 21.627 & 4,4,8-Trimethyl-non-7-en-2-one & $1.60 \times 10^{5}$ \\
\hline 21.775 & 6-Methyl-2-pyrazinylmethanol & $4.24 \times 10^{4}$ \\
\hline 21.930 & $\begin{array}{l}\text { Cyclopropanemethanol, } \alpha, 2 \text {-dimethyl-2-(4-methyl-3-pentenyl)-, } \\
\qquad\left[1 \alpha\left(R^{*}\right), 2 \alpha\right]-\end{array}$ & $4.83 \times 10^{4}$ \\
\hline 21.955 & Phenol & $5.52 \times 10^{4}$ \\
\hline 21.984 & Phosphonic acid, (p-hydroxyphenyl)- & $4.25 \times 10^{4}$ \\
\hline 22.301 & Nerolidyl acetate & $1.04 \times 10^{7}$ \\
\hline
\end{tabular}


Table A6. Cont.

\begin{tabular}{|c|c|c|}
\hline Retention Time & Name & Mean \\
\hline 22.522 & Octanoic acid & $3.00 \times 10^{5}$ \\
\hline 23.194 & 2-Pentadecanone, 6,10,14-trimethyl- & $2.62 \times 10^{4}$ \\
\hline 23.378 & $\begin{array}{l}\text { 2-Furanmethanol, } \\
\text { tetrahydro- } \alpha, \alpha, 5 \text {-trimethyl-5-(4-methyl-3-cyclohexen-1-yl)-, } \\
{\left[2 \mathrm{~S}-\left[2 \alpha, 5 \beta\left(\mathrm{R}^{*}\right)\right]\right]-}\end{array}$ & $9.90 \times 10^{5}$ \\
\hline 23.578 & 2(3H)-Furanone, 5-hexyldihydro- & $2.78 \times 10^{6}$ \\
\hline 23.925 & 2H-Pyran, 3,6-dihydro-4-methyl-2-(2-methyl-1-propenyl)- & $1.68 \times 10^{5}$ \\
\hline 24.136 & Epiglobulol & $3.83 \times 10^{5}$ \\
\hline 24.393 & Heptadecanal & $2.55 \times 10^{4}$ \\
\hline 25.829 & gamma.-Dodecalactone & $4.77 \times 10^{5}$ \\
\hline 26.403 & Benzoic acid & $4.52 \times 10^{5}$ \\
\hline 26.663 & Dodecanoic acid & $1.88 \times 10^{5}$ \\
\hline 26.955 & 5-Hydroxymethylfurfural & $1.16 \times 10^{5}$ \\
\hline 27.411 & 1,2-Benzenedicarboxylic acid, bis(2-methylpropyl) ester & $1.58 \times 10^{5}$ \\
\hline 27.726 & Decanoic acid, decyl ester & $1.44 \times 10^{5}$ \\
\hline 27.778 & 4a,8a-Butano[1,4]dioxino[2,3-b]-1,4-dioxin, tetrahydro- & $7.34 \times 10^{4}$ \\
\hline 27.810 & di(Butoxyethyl)adipate & $9.58 \times 10^{4}$ \\
\hline 29.208 & 2-Propanol, 1-chloro-, phosphate (3:1) & $5.56 \times 10^{4}$ \\
\hline
\end{tabular}

Table A7. SVL sample VOCs.

\begin{tabular}{ccc}
\hline Retention Time & Name & Mean \\
\hline 2.060 & Dimethyl sulfide & $8.70 \times 10^{5}$ \\
4.132 & Pentanal & $5.78 \times 10^{6}$ \\
5.156 & Butanoic acid, ethyl ester & $1.98 \times 10^{6}$ \\
6.135 & Hexanal & $7.04 \times 10^{5}$ \\
7.195 & Cyclopropanecarboxylic acid, 2-pentyl ester & $5.51 \times 10^{5}$ \\
9.353 & 1-Butanol, 3-methyl- & $3.11 \times 10^{5}$ \\
10.156 & Hexanoic acid, ethyl ester & $6.29 \times 10^{5}$ \\
10.516 & 1-Pentanol & $4.40 \times 10^{5}$ \\
11.356 & Acetoin & $9.62 \times 10^{5}$ \\
11.750 & 1-Octen-3-one & $4.22 \times 10^{5}$ \\
12.218 & 2-Heptenal, (Z)- & $8.23 \times 10^{5}$ \\
12.325 & 2,5-Hexanedione & $4.04 \times 10^{5}$ \\
12.553 & 5-Hepten-2-one, 6-methyl- & $6.21 \times 10^{5}$ \\
13.644 & Nonanal & $3.32 \times 10^{5}$ \\
13.851 & 2-Hexen-1-ol, (Z)- & $7.47 \times 10^{5}$ \\
14.281 & 2-Octenal, (E)- & $3.27 \times 10^{5}$ \\
14.485 & Ethyl 2-(5-methyl-5-vinyltetrahydrofuran-2-yl)propan-2-yl carbonate & $8.44 \times 10^{5}$ \\
14.708 & Ammonium acetate & $6.77 \times 10^{6}$ \\
14.952 & Furfural & $1.07 \times 10^{7}$ \\
15.264 & 2-Propyl-1-pentanol & $1.37 \times 10^{5}$ \\
15.591 & Ethanone, 1-(2-furanyl)- & $1.08 \times 10^{6}$ \\
15.893 & Benzaldehyde & $3.64 \times 10^{6}$ \\
16.159 & Propanoic acid, 2-methyl- & $9.20 \times 10^{6}$ \\
16.290 & 1-6-Octadien-3-ol,3,7-dimethyl- & $5.37 \times 10^{5}$ \\
16.559 & 1-Octanol & $3.53 \times 10^{5}$ \\
16.887 & (2)-Funothoxy-2,5-dimethyl- & $2.39 \times 10^{6}$ \\
17.239 & $1.73 \times 10^{5}$ \\
\hline
\end{tabular}


Table A7. Cont.

\begin{tabular}{|c|c|c|}
\hline Retention Time & Name & Mean \\
\hline 17.340 & Heptanoic acid & $4.50 \times 10^{5}$ \\
\hline 17.475 & Butanoic acid, 4-hydroxy- & $2.84 \times 10^{5}$ \\
\hline 17.727 & Acetophenone & $6.67 \times 10^{5}$ \\
\hline 17.914 & Butanoic acid, 2-methyl- & $2.87 \times 10^{6}$ \\
\hline 18.265 & L- $\alpha$-Terpineol & $4.02 \times 10^{6}$ \\
\hline 18.446 & Sulfurous acid, isohexyl hexyl ester & $4.11 \times 10^{5}$ \\
\hline 18.486 & Hexane, 3-bromo- & $3.00 \times 10^{5}$ \\
\hline 18.694 & Isocaryophillene & $7.36 \times 10^{5}$ \\
\hline 18.996 & Dimethylmalonic acid, monochloride, 2-octyl ester & $9.54 \times 10^{5}$ \\
\hline 19.245 & $5 \beta, 6 \beta$-Epoxy-7 $\alpha$-bromocholestan- $3 \beta$-ol & $3.92 \times 10^{5}$ \\
\hline 19.450 & Bicyclo[2.2.1] heptan-2-one, 1-(bromomethyl)-7,7-dimethyl-, (1S)- & $4.92 \times 10^{6}$ \\
\hline 20.088 & Heptanoic acid & $2.85 \times 10^{6}$ \\
\hline 20.254 & 2-Piperidinone, N-[4-bromo-n-butyl]- & $5.61 \times 10^{5}$ \\
\hline 20.523 & Benzyl alcohol & $6.02 \times 10^{5}$ \\
\hline 20.932 & Phenylethyl Alcohol & $2.00 \times 10^{5}$ \\
\hline 21.312 & Heptanoic acid & $6.97 \times 10^{4}$ \\
\hline 22.118 & Humulane-1,6-dien-3-ol & $9.67 \times 10^{4}$ \\
\hline 22.262 & Nerolidyl acetate & $1.11 \times 10^{7}$ \\
\hline 22.479 & Octanoic acid & $2.40 \times 10^{5}$ \\
\hline 22.852 & Cyclohexanone, 3-vinyl-3-methyl- & $6.77 \times 10^{4}$ \\
\hline 23.325 & $\begin{array}{l}\text { 2-Furanmethanol, } \\
\text { tetrahydro- } \alpha, \alpha, 5 \text {-trimethyl-5-(4-methyl-3-cyclohexen-1-yl)-, } \\
{\left[2 S-\left[2 \alpha, 5 \beta\left(\mathrm{R}^{*}\right)\right]\right]-}\end{array}$ & $3.96 \times 10^{5}$ \\
\hline 23.534 & 2(3H)-Furanone, 5-hexyldihydro- & $3.14 \times 10^{6}$ \\
\hline 23.925 & 8-Nonene-2,4-diol, 8-methyl-, $\left(\mathrm{R}^{*}, \mathrm{~S}^{*}\right)$ - & $2.18 \times 10^{5}$ \\
\hline 24.179 & Epiglobulol & $4.32 \times 10^{5}$ \\
\hline 25.788 & gamma.-Dodecalactone & $3.77 \times 10^{5}$ \\
\hline 26.351 & Benzoic acid & $7.12 \times 10^{5}$ \\
\hline 27.416 & 1,2-Benzenedicarboxylic acid, bis(2-methylpropyl) ester & $7.46 \times 10^{4}$ \\
\hline
\end{tabular}

Table A8. S100 sample VOCs.

\begin{tabular}{ccc}
\hline Retention Time & Name & Mean \\
\hline 2.091 & Dimethyl sulfide & $9.65 \times 10^{6}$ \\
4.130 & Pentanal & $6.03 \times 10^{6}$ \\
5.149 & Butanoic acid, ethyl ester & $1.90 \times 10^{6}$ \\
5.740 & 1-Penten-3-one, 2-methyl- & $8.67 \times 10^{5}$ \\
6.109 & Hexanal & $1.73 \times 10^{6}$ \\
7.168 & 3-Buten-2-one, 3-methyl- & $7.64 \times 10^{5}$ \\
8.992 & Cyclobutane, 1,2-bis(1-methylethenyl)-, trans- & $1.69 \times 10^{7}$ \\
10.334 & gamma--Terpinene & $1.60 \times 10^{6}$ \\
10.500 & 1-Pentanol & $2.75 \times 10^{5}$ \\
10.982 & o-Cymene & $6.16 \times 10^{5}$ \\
11.343 & Acetoin & $6.90 \times 10^{5}$ \\
11.455 & Octanal & $2.79 \times 10^{5}$ \\
11.500 & Nonanal & $4.33 \times 10^{5}$ \\
\hline
\end{tabular}


Table A8. Cont.

\begin{tabular}{|c|c|c|}
\hline Retention Time & Name & Mean \\
\hline 11.742 & 1-Octen-3-one & $8.99 \times 10^{5}$ \\
\hline 12.210 & 2-Heptenal, (Z)- & $2.60 \times 10^{6}$ \\
\hline 12.529 & 5-Hepten-2-one, 6-methyl- & $1.22 \times 10^{6}$ \\
\hline 13.807 & 2-Octene, 2-methyl-6-methylene- & $7.11 \times 10^{5}$ \\
\hline 14.274 & 2-Octenal, $(\mathrm{E})-$ & $8.26 \times 10^{5}$ \\
\hline 14.479 & Ethyl 2-(5-methyl-5-vinyltetrahydrofuran-2-yl)propan-2-yl carbonate & $1.72 \times 10^{6}$ \\
\hline 14.704 & Ammonium acetate & $7.92 \times 10^{6}$ \\
\hline 14.942 & Furfural & $1.88 \times 10^{7}$ \\
\hline 15.259 & 1-Hexanol, 2-ethyl- & $2.08 \times 10^{6}$ \\
\hline 15.585 & Ethanone, 1-(2-furanyl)- & $1.67 \times 10^{6}$ \\
\hline 15.890 & Benzaldehyde & $1.55 \times 10^{7}$ \\
\hline 16.153 & 1,6-Octadien-3-ol, 3,7-dimethyl- & $9.33 \times 10^{6}$ \\
\hline 16.285 & 1-Octanol & $7.25 \times 10^{5}$ \\
\hline 16.420 & $\begin{array}{l}\text { 2H-1,4-Benzodiazepin-2-one, } \\
\text { 7-chloro-1,3-dihydro-5-phenyl-1-(trimethylsilyl)- }\end{array}$ & $5.76 \times 10^{5}$ \\
\hline 16.708 & Bicyclo[2.2.1]heptan-2-ol, 1,3,3-trimethyl- & $1.06 \times 10^{6}$ \\
\hline 16.883 & 3(2H)-Furanone, 4-methoxy-2,5-dimethyl- & $2.25 \times 10^{6}$ \\
\hline 16.980 & 3-Cyclohexen-1-ol, 4-methyl-1-(1-methylethyl)-, (R)- & $8.76 \times 10^{5}$ \\
\hline 17.146 & 2-Decen-1-ol, (E)- & $2.09 \times 10^{5}$ \\
\hline 17.355 & Cyclohexanol, 1-methyl-4-(1-methylethenyl)- & $1.17 \times 10^{6}$ \\
\hline 17.454 & Butanoic acid, 4-hydroxy- & $6.96 \times 10^{5}$ \\
\hline 17.727 & Acetophenone & $1.52 \times 10^{6}$ \\
\hline 17.906 & Butanoic acid, 2-methyl- & $3.27 \times 10^{6}$ \\
\hline 18.260 & L- $\alpha$-Terpineol & $1.15 \times 10^{7}$ \\
\hline 18.686 & Isocaryophillene & $9.64 \times 10^{5}$ \\
\hline 18.989 & 1, 1, 5-Trimethyl-1, 2-dihydronaphthalene & $9.34 \times 10^{5}$ \\
\hline 19.237 & $5 \alpha$-Cholestan-2-one, oxime & $3.48 \times 10^{5}$ \\
\hline 19.442 & Bicyclo[2.2.1]heptan-2-one, 1-(bromomethyl)-7,7-dimethyl-, (1S)- & $4.56 \times 10^{6}$ \\
\hline 20.084 & Heptanoic acid & $3.32 \times 10^{6}$ \\
\hline 20.243 & 5,9-Undecadien-2-one, 6,10-dimethyl-, (Z)- & $6.78 \times 10^{5}$ \\
\hline 20.516 & Benzyl alcohol & $2.44 \times 10^{6}$ \\
\hline 20.928 & Phenylethyl Alcohol & $4.36 \times 10^{5}$ \\
\hline 21.308 & Stevioside & $1.47 \times 10^{5}$ \\
\hline 22.071 & $\alpha$-Cadinol & $5.56 \times 10^{6}$ \\
\hline 22.261 & Nerolidyl acetate & $1.33 \times 10^{6}$ \\
\hline 22.478 & Octanoic acid & $2.87 \times 10^{5}$ \\
\hline 23.328 & $\begin{array}{l}\text { 2-Furanmethanol, } \\
\text { tetrahydro- } \alpha, \alpha, 5 \text {-trimethyl-5-(4-methyl-3-cyclohexen-1-yl)-, } \\
{\left[2 \mathrm{~S}-\left[2 \alpha, 5 \beta\left(\mathrm{R}^{*}\right)\right]\right]-}\end{array}$ & $5.57 \times 10^{5}$ \\
\hline 23.528 & 2(3H)-Furanone, 5-hexyldihydro- & $3.30 \times 10^{6}$ \\
\hline 23.930 & 2-Methyl-7-oxabicyclo[2.2.1]heptane & $3.06 \times 10^{5}$ \\
\hline 24.140 & Propanoic acid, 2-(3-acetoxy-4,4,14-trimethylandrost-8-en-17-yl)- & $3.31 \times 10^{5}$ \\
\hline 25.779 & 2(3H)-Furanone, 5-heptyldihydro- & $4.20 \times 10^{5}$ \\
\hline 26.346 & Benzoic acid & $7.84 \times 10^{5}$ \\
\hline
\end{tabular}


Table A9. SL sample VOCs.

\begin{tabular}{|c|c|c|}
\hline Retention Time & Name & Mean \\
\hline 2.905 & Ethyl Acetate & $1.46 \times 10^{6}$ \\
\hline 5.460 & Butanoic acid, 2-methyl-, ethyl ester & $3.57 \times 10^{5}$ \\
\hline 10.195 & Hexanoic acid, ethyl ester & $4.05 \times 10^{5}$ \\
\hline 11.416 & Acetoin & $7.36 \times 10^{5}$ \\
\hline 11.774 & 2-Cyclopenten-1-one, 3-(acetyloxy)- & $1.40 \times 10^{5}$ \\
\hline 14.430 & Octanoic acid, ethyl ester & $7.50 \times 10^{4}$ \\
\hline 14.527 & Ethyl 2-(5-methyl-5-vinyltetrahydrofuran-2-yl)propan-2-yl carbonate & $7.97 \times 10^{5}$ \\
\hline 14.670 & 1-Octen-3-ol & $1.64 \times 10^{5}$ \\
\hline 14.771 & Ammonium acetate & $4.18 \times 10^{6}$ \\
\hline 14.999 & Furfural & $1.23 \times 10^{7}$ \\
\hline 15.315 & 1-Hexanol, 2-ethyl- & $5.59 \times 10^{5}$ \\
\hline 15.634 & Ethanone, 1-(2-furanyl)- & $1.48 \times 10^{6}$ \\
\hline 15.936 & Benzaldehyde & $1.24 \times 10^{7}$ \\
\hline 16.199 & 1,6-Octadien-3-ol, 3,7-dimethyl- & $2.35 \times 10^{6}$ \\
\hline 16.341 & 1-Octanol & $7.98 \times 10^{5}$ \\
\hline 16.686 & 2-Furancarboxaldehyde, 5-methyl- & $3.77 \times 10^{5}$ \\
\hline 16.933 & 3(2H)-Furanone, 4-methoxy-2,5-dimethyl- & $9.20 \times 10^{5}$ \\
\hline 17.115 & 9-Methyl-10,12-hexadecadien-1-ol acetate & $2.87 \times 10^{5}$ \\
\hline 17.245 & Methoxyacetic acid, 2-pentyl ester & $2.67 \times 10^{5}$ \\
\hline 17.394 & Heptanoic acid & $4.50 \times 10^{5}$ \\
\hline 17.511 & Decanoic acid, ethyl ester & $3.77 \times 10^{5}$ \\
\hline 17.774 & Acetophenone & $8.89 \times 10^{5}$ \\
\hline 17.967 & Butanoic acid, 2-methyl- & $1.59 \times 10^{6}$ \\
\hline 18.165 & Octadecane-1,2-diol, bis(trimethylsilyl) ether & $4.53 \times 10^{5}$ \\
\hline 18.309 & L- $\alpha$-Terpineol & $1.47 \times 10^{6}$ \\
\hline 18.495 & 1,5-Heptadien-4-ol, 3,3,6-trimethyl- & $3.54 \times 10^{5}$ \\
\hline 18.729 & Bicyclo[5.2.0]nonane, 2-methylene-4,8,8-trimethyl-4-vinyl- & $2.31 \times 10^{5}$ \\
\hline 19.035 & Oxime-, methoxy-phenyl-_ & $7.19 \times 10^{5}$ \\
\hline 19.263 & $5 \alpha$-Cholestan-2-one, oxime & $2.35 \times 10^{5}$ \\
\hline 19.484 & Bicyclo[2.2.1]heptan-2-one, 1-(bromomethyl)-7,7-dimethyl-, (1S)- & $2.41 \times 10^{6}$ \\
\hline 20.141 & Heptanoic acid & $1.24 \times 10^{6}$ \\
\hline 20.573 & Benzyl alcohol & $2.85 \times 10^{5}$ \\
\hline 20.975 & Phenylethyl Alcohol & $2.22 \times 10^{5}$ \\
\hline 21.084 & 2,6-Bis(1,1-dimethylethyl)-4-(1-oxopropyl)phenol & $7.42 \times 10^{4}$ \\
\hline 21.353 & Heptanoic acid & $2.65 \times 10^{5}$ \\
\hline 21.486 & Formic acid, decyl ester & $2.65 \times 10^{5}$ \\
\hline 22.300 & Nerolidyl acetate & $4.41 \times 10^{6}$ \\
\hline 22.531 & Octanoic acid & $4.04 \times 10^{5}$ \\
\hline 23.376 & $\begin{array}{l}\text { 2-Furanmethanol, } \\
\text { tetrahydro- } \alpha, \alpha, 5 \text {-trimethyl-5-(4-methyl-3-cyclohexen-1-yl)-, } \\
{\left[2 \mathrm{~S}-\left[2 \alpha, 5 \beta\left(\mathrm{R}^{*}\right)\right]\right]-}\end{array}$ & $5.82 \times 10^{5}$ \\
\hline 23.579 & 2(3H)-Furanone, 5-hexyldihydro- & $7.91 \times 10^{5}$ \\
\hline 23.790 & $\begin{array}{l}\text { Acetohydrazide, } \\
\text { 2-(4-morpholyl)-N2-[(4-methylcyclohex-3-enyl)methylene]- }\end{array}$ & $2.98 \times 10^{5}$ \\
\hline 24.538 & $\begin{array}{c}\text { 1-(3,3-Dimethyl-but-1-ynyl)-2,2,3,3-tetramethylcyclopropanecarboxylic } \\
\text { acid }\end{array}$ & $9.59 \times 10^{4}$ \\
\hline 24.682 & n-Decanoic acid & $1.67 \times 10^{5}$ \\
\hline 25.830 & 2(3H)-Furanone, 5-heptyldihydro- & $2.25 \times 10^{5}$ \\
\hline 26.429 & Benzoic acid & $3.39 \times 10^{5}$ \\
\hline 26.552 & 5H-1-Pyrindine & $5.89 \times 10^{5}$ \\
\hline 26.983 & 5-Hydroxymethylfurfural & $2.03 \times 10^{5}$ \\
\hline
\end{tabular}


Table A10. SS sample VOCs.

\begin{tabular}{|c|c|c|}
\hline Retention Time & Name & Mean \\
\hline 1.763 & N-Methylallylamine & $1.15 \times 10^{7}$ \\
\hline 2.395 & Acetone & $1.28 \times 10^{7}$ \\
\hline 2.865 & Ethyl Acetate & $5.66 \times 10^{6}$ \\
\hline 3.335 & Ethanol & $4.63 \times 10^{6}$ \\
\hline 4.055 & 2,3-Butanedione & $1.56 \times 10^{6}$ \\
\hline 10.108 & Hexanoic acid, ethyl ester & $3.14 \times 10^{5}$ \\
\hline 10.671 & Acetoin & $1.40 \times 10^{6}$ \\
\hline 11.754 & Heptane, 2,3-dimethyl- & $2.52 \times 10^{5}$ \\
\hline 12.183 & 1-Heptanol, 2-propyl- & $1.28 \times 10^{5}$ \\
\hline 13.503 & $\mathrm{CH} 3 \mathrm{C}(\mathrm{O}) \mathrm{OCH}(\mathrm{CH} 3) \mathrm{C}(\mathrm{O}) \mathrm{CH} 3$ & $2.00 \times 10^{5}$ \\
\hline 14.295 & 2-Octenal, $(\mathrm{E})$ - & $5.69 \times 10^{5}$ \\
\hline 14.505 & Ethyl 2-(5-methyl-5-vinyltetrahydrofuran-2-yl)propan-2-yl carbonate & $1.23 \times 10^{6}$ \\
\hline 14.649 & Ammonium acetate & $6.22 \times 10^{6}$ \\
\hline 14.823 & Furfural & $1.35 \times 10^{7}$ \\
\hline 15.616 & Ethanone, 1-(2-furanyl)- & $9.83 \times 10^{5}$ \\
\hline 15.795 & Benzaldehyde & $2.34 \times 10^{7}$ \\
\hline 16.123 & 1,6-Octadien-3-ol, 3,7-dimethyl- & $3.87 \times 10^{6}$ \\
\hline 16.245 & 2,3,4-Trifluorobenzoic acid, 4-tetradecyl ester & $1.01 \times 10^{6}$ \\
\hline 16.848 & $3(2 \mathrm{H})$-Furanone, 4-methoxy-2,5-dimethyl- & $6.99 \times 10^{5}$ \\
\hline 17.343 & n-Decanoic acid & $4.52 \times 10^{5}$ \\
\hline 17.498 & Butanoic acid, 4-hydroxy- & $2.58 \times 10^{5}$ \\
\hline 17.769 & Acetophenone & $1.21 \times 10^{6}$ \\
\hline 17.926 & Butanoic acid, 2-methyl- & $1.78 \times 10^{6}$ \\
\hline 18.264 & L- $\alpha$-Terpineol & $2.98 \times 10^{6}$ \\
\hline 18.695 & Bicyclo[5.2.0]nonane, 2-methylene-4,8,8-trimethyl-4-vinyl- & $3.43 \times 10^{5}$ \\
\hline 18.968 & Oxime-, methoxy-phenyl-_ & $2.32 \times 10^{6}$ \\
\hline 19.457 & Bicyclo[2.2.1] heptan-2-one, 1-(bromomethyl)-7,7-dimethyl-, (1S)- & $2.02 \times 10^{6}$ \\
\hline 20.119 & Cyclopentylcarboxylic acid & $1.72 \times 10^{6}$ \\
\hline 20.529 & Benzyl alcohol & $5.73 \times 10^{5}$ \\
\hline 20.962 & Phenylethyl Alcohol & $4.96 \times 10^{5}$ \\
\hline 21.337 & Heptanoic acid & $2.65 \times 10^{5}$ \\
\hline 21.464 & 1-Dodecanol & $4.72 \times 10^{5}$ \\
\hline 21.785 & 5-Methyl-2-pyrazinylmethanol & $2.17 \times 10^{5}$ \\
\hline 22.014 & Phosphonic acid, (p-hydroxyphenyl)- & $2.39 \times 10^{5}$ \\
\hline 22.105 & 2-Butanone, 4-(2,6,6-trimethyl-2-cyclohexen-1-yl)- & $5.26 \times 10^{5}$ \\
\hline 22.279 & Nerolidyl acetate & $7.69 \times 10^{6}$ \\
\hline 22.506 & Octanoic acid & $3.98 \times 10^{5}$ \\
\hline 23.234 & Tetradecanal & $1.39 \times 10^{6}$ \\
\hline 23.558 & 2(3H)-Furanone, 5-hexyldihydro- & $1.06 \times 10^{6}$ \\
\hline 23.769 & Formic acid, 2,3-dimethylphenyl ester & $2.92 \times 10^{5}$ \\
\hline 24.175 & Viridiflorol & $8.36 \times 10^{5}$ \\
\hline 24.627 & Decanoic acid, silver(1+) salt & $3.79 \times 10^{5}$ \\
\hline 25.025 & Phenol, 2,6-bis(1,1-dimethylethyl)- & $1.99 \times 10^{5}$ \\
\hline 26.374 & Benzoic acid & $4.74 \times 10^{6}$ \\
\hline 26.954 & 5-Hydroxymethylfurfural & $4.34 \times 10^{5}$ \\
\hline 27.777 & Decanoic acid, cyclohexyl ester & $3.41 \times 10^{5}$ \\
\hline
\end{tabular}


Table A11. CPS sample VOCs.

\begin{tabular}{|c|c|c|}
\hline Retention Time & Name & Mean \\
\hline 1.745 & Hydroperoxide, pentyl & $1.06 \times 10^{7}$ \\
\hline 8.171 & $\beta$-Myrcene & $1.75 \times 10^{7}$ \\
\hline 8.266 & D-Limonene & $8.70 \times 10^{8}$ \\
\hline 10.300 & Benzenemethanimine & $1.26 \times 10^{6}$ \\
\hline 10.985 & Benzene, 1-methyl-3-(1-methylethyl)- & $9.98 \times 10^{5}$ \\
\hline 11.270 & $(+)-4$-Carene & $2.73 \times 10^{6}$ \\
\hline 13.630 & Nonanal & $1.18 \times 10^{6}$ \\
\hline 14.387 & Octanoic acid, ethyl ester & $2.28 \times 10^{6}$ \\
\hline 14.700 & Acetic acid & $2.76 \times 10^{6}$ \\
\hline 14.943 & Furfural & $5.77 \times 10^{6}$ \\
\hline 15.258 & 2-Propyl-1-pentanol & $1.46 \times 10^{6}$ \\
\hline 15.324 & $\alpha$-Copaene & $1.17 \times 10^{6}$ \\
\hline 15.881 & Benzaldehyde & $1.04 \times 10^{7}$ \\
\hline 16.155 & 1,6-Octadien-3-ol, 3,7-dimethyl- & $1.87 \times 10^{6}$ \\
\hline 16.297 & 1-Octanol & $1.74 \times 10^{6}$ \\
\hline 16.835 & $\begin{array}{l}\text { Cyclohexane, 1-ethenyl-1-methyl-2,4-bis(1-methylethenyl)-, } \\
{[1 \mathrm{~S}-(1 \alpha, 2 \beta, 4 \beta)]-}\end{array}$ & $2.08 \times 10^{5}$ \\
\hline 16.967 & Bicyclo[7.2.0]undec-4-ene, 4,11,11-trimethyl-8-methylene- & $4.18 \times 10^{6}$ \\
\hline 17.366 & Cyclohexanol, 1-methyl-4-(1-methylethenyl)- & $3.91 \times 10^{6}$ \\
\hline 18.048 & p-Menth-8-en-1-ol, stereoisomer & $7.96 \times 10^{5}$ \\
\hline 18.264 & L- $\alpha$-Terpineol & $2.01 \times 10^{7}$ \\
\hline 18.679 & $\begin{array}{l}\text { 1.4-Methano-1H-indene, } \\
\text { octahydro-4-methyl-8-methylene-7-(1-methylethyl)-, } \\
{[1 S-(1 \alpha, 3 a \beta, 4 \alpha, 7 \alpha, 7 \mathrm{a} \beta)]-}\end{array}$ & $7.58 \times 10^{5}$ \\
\hline 19.101 & $\begin{array}{l}\text { Naphthalene, 1,2,3,5,6,8a-hexahydro-4,7-dimethyl-1-(1-methylethyl)-, } \\
\text { (1S-cis)- }\end{array}$ & $1.09 \times 10^{6}$ \\
\hline 20.075 & 5-Hexenoic acid, 5-methyl- & $2.54 \times 10^{5}$ \\
\hline 20.242 & 5,9-Undecadien-2-one, 6,10-dimethyl-, (Z)- & $1.86 \times 10^{5}$ \\
\hline 20.513 & Benzyl alcohol & $3.75 \times 10^{6}$ \\
\hline 20.924 & Phenylethyl Alcohol & $1.81 \times 10^{5}$ \\
\hline 26.307 & Benzoic acid & $5.70 \times 10^{5}$ \\
\hline
\end{tabular}


Table A12. CVL sample VOCs.

\begin{tabular}{|c|c|c|}
\hline Retention Time & Name & Mean \\
\hline 2.394 & 1H-Tetrazole-1,5-diamine & $1.62 \times 10^{6}$ \\
\hline 2.530 & Acetic acid, 2-[(acetyl)(2,2-dicyanoethenyl)amino]-, ethyl ester & $5.84 \times 10^{4}$ \\
\hline 3.401 & Ethanol & $5.19 \times 10^{5}$ \\
\hline 9.374 & 1-Butanol, 3-methyl- & $2.60 \times 10^{5}$ \\
\hline 11.348 & Acetoin & $4.80 \times 10^{5}$ \\
\hline 13.279 & 4-Dodecyne & $1.55 \times 10^{5}$ \\
\hline 13.650 & Nonanal & $3.49 \times 10^{5}$ \\
\hline 13.855 & 2-Hexen-1-ol, (E)- & $3.83 \times 10^{5}$ \\
\hline 14.485 & Ethyl 2-(5-methyl-5-vinyltetrahydrofuran-2-yl)propan-2-yl carbonate & $2.43 \times 10^{5}$ \\
\hline 14.718 & Ammonium acetate & $2.03 \times 10^{6}$ \\
\hline 14.949 & Furfural & $9.86 \times 10^{6}$ \\
\hline 15.265 & 1-Hexanol, 2-ethyl- & $1.65 \times 10^{5}$ \\
\hline 15.590 & Ethanone, 1-(2-furanyl)- & $1.03 \times 10^{6}$ \\
\hline 15.890 & Benzaldehyde & $4.14 \times 10^{6}$ \\
\hline 16.159 & 1,6-Octadien-3-ol, 3,7-dimethyl- & $2.42 \times 10^{6}$ \\
\hline 16.290 & 1-Octanol & $3.22 \times 10^{5}$ \\
\hline 16.632 & 2-Furancarboxaldehyde, 5-methyl- & $3.47 \times 10^{5}$ \\
\hline 16.855 & 1-Propene, 3-chloro-2-(chloromethyl)- & $1.00 \times 10^{5}$ \\
\hline 16.979 & 3-Cyclohexen-1-ol, 4-methyl-1-(1-methylethyl)-, (R)- & $2.04 \times 10^{5}$ \\
\hline 17.249 & 2H-Pyran-2-one, tetrahydro- & $4.80 \times 10^{5}$ \\
\hline 17.454 & Butyrolactone & $6.61 \times 10^{5}$ \\
\hline 17.913 & Butanoic acid, 2-methyl- & $3.15 \times 10^{5}$ \\
\hline 18.162 & 1,7-Dimethyl-4-oxa-tricyclo[5.2.1.0(2,6)]decane-3,5,8-trione & $2.57 \times 10^{5}$ \\
\hline 18.268 & L- $\alpha$-Terpineol & $1.07 \times 10^{6}$ \\
\hline 18.484 & Methyl 7,9-tridecadienyl ether & $1.62 \times 10^{5}$ \\
\hline 18.989 & 1, 1,5-Trimethyl-1, 2-dihydronaphthalene & $6.88 \times 10^{5}$ \\
\hline 20.090 & Heptanoic acid & $8.43 \times 10^{5}$ \\
\hline 20.262 & $(1 \mathrm{R}, 2 \mathrm{R}, 3 \mathrm{R}, 5 \mathrm{~S})-(-)$-Isopinocampheol & $3.04 \times 10^{5}$ \\
\hline 20.519 & Benzyl alcohol & $3.19 \times 10^{6}$ \\
\hline 20.716 & 4-Acetyl-1-methylcyclohexene & $1.44 \times 10^{5}$ \\
\hline 20.928 & Phenylethyl Alcohol & $2.74 \times 10^{5}$ \\
\hline 21.292 & $\begin{array}{l}\text { Acetic acid, } \\
\text { 6,6-dimethyl-2-methylene-7-(3-oxobutylidene)oxepan-3-ylmethyl ester }\end{array}$ & $1.43 \times 10^{5}$ \\
\hline 22.258 & Nerolidyl acetate & $2.45 \times 10^{5}$ \\
\hline 23.365 & Octadecanal & $2.70 \times 10^{5}$ \\
\hline 23.535 & 2(3H)-Furanone, 5-hexyldihydro- & $3.88 \times 10^{5}$ \\
\hline 23.715 & Phenol, 2-methoxy-3-(2-propenyl)- & $7.59 \times 10^{4}$ \\
\hline 25.785 & Ethanol, 2-[2-[(tetrahydro-2H-pyran-2-yl)oxy]ethoxy]- & $2.81 \times 10^{4}$ \\
\hline 25.850 & 8-Methyl-hexahydro-pyrano[3,2-b]pyran-2-one & $7.16 \times 10^{4}$ \\
\hline 26.347 & Benzoic acid & $5.87 \times 10^{5}$ \\
\hline 26.645 & 2-Propenoic acid, 3-(2-hydroxyphenyl)-, (E)- & $3.05 \times 10^{5}$ \\
\hline 29.615 & $\begin{array}{l}\text { 2-[2-[2-[2-[2-[2-[2-[2-[2-(2-Methoxyethoxy)ethoxy]ethoxy] } \\
\text { ethoxy]ethoxy]ethoxy]ethoxy] ethoxy]ethoxy]ethanol }\end{array}$ & $3.46 \times 10^{4}$ \\
\hline
\end{tabular}


Table A13. C100 sample VOCs.

\begin{tabular}{|c|c|c|}
\hline Retention Time & Name & Mean \\
\hline 2.375 & 2-Heptanone, 7,7-dichloro- & $7.84 \times 10^{5}$ \\
\hline 3.379 & Ethanol & $2.22 \times 10^{5}$ \\
\hline 4.730 & 11H-Naphtho[1,2-b]thieno[3,4-d]pyran-11-one, 1-amino-3-methyl- & $1.47 \times 10^{6}$ \\
\hline 8.998 & Cyclobutane, 1,2-bis(1-methylethenyl)-, trans- & $9.23 \times 10^{6}$ \\
\hline 10.336 & gamma.-Terpinene & $8.00 \times 10^{5}$ \\
\hline 10.986 & Benzene, 1,2,4,5-tetramethyl- & $1.98 \times 10^{5}$ \\
\hline 11.346 & Acetoin & $5.52 \times 10^{5}$ \\
\hline 12.583 & 2,6-Lutidine 3,5-dichloro-4-dodecylthio- & $6.28 \times 10^{4}$ \\
\hline 13.268 & 7-Oxabicyclo[4.1.0]heptane, 1-methyl-4-(1-methylethenyl)- & $8.64 \times 10^{4}$ \\
\hline 13.525 & Acetic acid, 2-ethylhexyl ester & $8.29 \times 10^{3}$ \\
\hline 13.642 & Nonanal & $2.11 \times 10^{5}$ \\
\hline 13.848 & 2-Hexen-1-ol, (E)- & $3.27 \times 10^{5}$ \\
\hline 14.475 & Ethyl 2-(5-methyl-5-vinyltetrahydrofuran-2-yl)propan-2-yl carbonate & $5.11 \times 10^{5}$ \\
\hline 14.712 & Ammonium acetate & $2.00 \times 10^{6}$ \\
\hline 14.945 & Furfural & $7.46 \times 10^{6}$ \\
\hline 15.261 & 1-Hexanol, 2-ethyl- & $1.37 \times 10^{6}$ \\
\hline 15.585 & Ethanone, 1-(2-furanyl)- & $8.11 \times 10^{5}$ \\
\hline 15.897 & Benzaldehyde & $2.52 \times 10^{6}$ \\
\hline 16.155 & 1,6-Octadien-3-ol, 3,7-dimethyl- & $1.83 \times 10^{6}$ \\
\hline 16.289 & 1-Octanol & $1.94 \times 10^{5}$ \\
\hline 16.650 & 3-Cyclohexen-1-ol, 1-methyl-4-(1-methylethyl)- & $1.53 \times 10^{5}$ \\
\hline 16.713 & Bicyclo[2.2.1]heptan-2-ol, 1,3,3-trimethyl- & $5.69 \times 10^{5}$ \\
\hline 16.982 & 3-Cyclohexen-1-ol, 4-methyl-1-(1-methylethyl)-, (R)- & $8.19 \times 10^{5}$ \\
\hline 17.259 & 2(3H)-Furanone, dihydro-4-methyl- & $2.91 \times 10^{5}$ \\
\hline 17.360 & p-Menth-8-en-1-ol, stereoisomer & $7.02 \times 10^{4}$ \\
\hline 17.421 & Cyclohexanol, 1-methyl-4-(1-methylethenyl)- & $1.00 \times 10^{6}$ \\
\hline 17.775 & 2-Furanmethanol & $2.19 \times 10^{5}$ \\
\hline 17.910 & Butanoic acid, 2-methyl- & $5.10 \times 10^{5}$ \\
\hline 18.262 & L- $\alpha$-Terpineol & $7.82 \times 10^{6}$ \\
\hline 18.679 & $\begin{array}{c}\text { 1H-Benzocycloheptene, } \\
2,4 \mathrm{a}, 5,6,7,8,9,9 \mathrm{a}-\text { octahydro-3,5,5-trimethyl-9-methylene- }\end{array}$ & $3.33 \times 10^{5}$ \\
\hline 18.817 & Carvone & $1.42 \times 10^{5}$ \\
\hline 19.010 & Naphthalene, 1,2-dihydro-1,5,8-trimethyl- & $4.19 \times 10^{5}$ \\
\hline 19.152 & $\begin{array}{l}\text { Naphthalene, 1,2,3,5,6,8a-hexahydro-4,7-dimethyl-1-(1-methylethyl)-, } \\
\text { (1S-cis)- }\end{array}$ & $1.20 \times 10^{5}$ \\
\hline 20.086 & Heptanoic acid & $8.43 \times 10^{5}$ \\
\hline 20.250 & 5,9-Undecadien-2-one, 6,10-dimethyl-, (E)- & $2.22 \times 10^{5}$ \\
\hline 20.720 & Nona-3,5-dien-2-one & $1.01 \times 10^{5}$ \\
\hline 20.931 & Phenylethyl Alcohol & $4.73 \times 10^{5}$ \\
\hline 21.295 & $\begin{array}{l}\text { Acetic acid, } \\
\text { 6,6-dimethyl-2-methylene-7-(3-oxobutylidene)oxepan-3-ylmethyl ester }\end{array}$ & $8.99 \times 10^{4}$ \\
\hline 22.255 & 1,6,10-Dodecatrien-3-ol, 3,7,11-trimethyl-, [S-(Z)]- & $2.74 \times 10^{5}$ \\
\hline 23.532 & 2(3H)-Furanone, 5-hexyldihydro- & $3.99 \times 10^{5}$ \\
\hline 23.711 & Phenol, 2-methoxy-3-(2-propenyl)- & $1.45 \times 10^{5}$ \\
\hline 25.853 & .gamma.-Dodecalactone & $5.64 \times 10^{4}$ \\
\hline 26.354 & Benzoic acid & $3.24 \times 10^{5}$ \\
\hline
\end{tabular}


Table A14. CL sample VOCs.

\begin{tabular}{|c|c|c|}
\hline Retention Time & Name & Mean \\
\hline 2.511 & Ethyl Acetate & $1.78 \times 10^{6}$ \\
\hline 12.525 & 5-Hepten-2-one, 6-methyl- & $1.16 \times 10^{5}$ \\
\hline 13.279 & 7-Oxabicyclo[4.1.0]heptane, 1-methyl-4-(1-methylethenyl)- & $8.60 \times 10^{4}$ \\
\hline 13.667 & Nonanal & $1.08 \times 10^{5}$ \\
\hline 13.790 & 1H-Pyrazole, 4,5-dihydro-5,5-dimethyl-4-isopropylidene- & $3.13 \times 10^{5}$ \\
\hline 14.505 & $\alpha$-Methyl- $\alpha$-[4-methyl-3-pentenyl]oxiranemethanol & $8.22 \times 10^{4}$ \\
\hline 14.625 & Sulfurous acid, hexyl octyl ester & $1.15 \times 10^{5}$ \\
\hline 14.779 & Ammonium acetate & $1.03 \times 10^{6}$ \\
\hline 14.990 & Furfural & $1.51 \times 10^{7}$ \\
\hline 15.305 & Acetic acid, dichloro-, heptyl ester & $7.47 \times 10^{5}$ \\
\hline 15.636 & Ethanone, 1-(2-furanyl)- & $1.83 \times 10^{6}$ \\
\hline 15.931 & Benzaldehyde & $4.84 \times 10^{7}$ \\
\hline 16.195 & 1,6-Octadien-3-ol, 3,7-dimethyl- & $1.05 \times 10^{6}$ \\
\hline 16.345 & 2,3,4-Trifluorobenzoic acid, 4-tetradecyl ester & $3.43 \times 10^{5}$ \\
\hline 16.672 & 2-Furancarboxaldehyde, 5-methyl- & $4.21 \times 10^{5}$ \\
\hline 17.273 & Ethanol, 2-(2-ethoxyethoxy)- & $1.68 \times 10^{5}$ \\
\hline 17.327 & 1-Cyclohexene-1-carboxaldehyde, 2,6,6-trimethyl- & $2.80 \times 10^{5}$ \\
\hline 17.498 & Butanoic acid, 4-hydroxy- & $4.08 \times 10^{5}$ \\
\hline 17.968 & Butanoic acid, 2-methyl- & $1.77 \times 10^{5}$ \\
\hline 18.305 & L- $\alpha$-Terpineol & $1.20 \times 10^{6}$ \\
\hline 18.521 & Dodecanal & $2.45 \times 10^{5}$ \\
\hline 18.785 & 1H-Imidazole, 4,5-dimethyl- & $9.47 \times 10^{4}$ \\
\hline 18.903 & $\begin{array}{l}\text { Naphthalene, decahydro-1,4a-dimethyl-7-(1-methylethyl)-, } \\
\text { [1S- }(1 \alpha, 4 \mathrm{a} \alpha, 7 \alpha, 8 \mathrm{a} \beta)]-\end{array}$ & $6.00 \times 10^{5}$ \\
\hline 19.026 & 1, 1, 5-Trimethyl-1, 2-dihydronaphthalene & $1.42 \times 10^{6}$ \\
\hline 19.277 & N-Acetyl-2-ethylbutan-1-amine & $1.38 \times 10^{4}$ \\
\hline 20.132 & Heptanoic acid & $5.47 \times 10^{5}$ \\
\hline 20.284 & 6,8-Nonadien-2-one, 8-methyl-5-(1-methylethyl)-, (E)- & $2.48 \times 10^{5}$ \\
\hline 20.561 & Benzyl alcohol & $1.01 \times 10^{6}$ \\
\hline 20.755 & 4-Acetyl-1-methylcyclohexene & $1.70 \times 10^{5}$ \\
\hline 20.965 & Phenol, 2,6-bis(1,1-dimethylethyl)-4-methyl-, methylcarbamate & $2.86 \times 10^{5}$ \\
\hline 21.085 & 2,6-Bis(1,1-dimethylethyl)-4-(1-oxopropyl)phenol & $1.73 \times 10^{5}$ \\
\hline 21.316 & 2-Butanone, 4-(2,6,6-trimethyl-2-cyclohexen-1-ylidene)- & $2.91 \times 10^{5}$ \\
\hline 21.477 & 1-Dodecanol & $2.12 \times 10^{5}$ \\
\hline 21.809 & 6-Methyl-2-pyrazinylmethanol & $2.53 \times 10^{5}$ \\
\hline 22.010 & Acetic acid, phenyl ester & $1.72 \times 10^{5}$ \\
\hline 22.526 & Octanoic acid & $2.46 \times 10^{5}$ \\
\hline 23.244 & $\begin{array}{l}\text { 1H-Indene-4-acetic acid, } \\
\text { 6-(1,1-dimethylethyl)-2,3-dihydro-1,1-dimethyl- }\end{array}$ & $1.31 \times 10^{5}$ \\
\hline 23.641 & Pentadecanoic acid & $2.94 \times 10^{5}$ \\
\hline 23.757 & Eugenol & $4.60 \times 10^{5}$ \\
\hline 24.541 & $\begin{array}{c}\text { 1-(3,3-Dimethyl-but-1-ynyl)-2,2,3,3-tetramethylcyclopropanecarboxylic } \\
\text { acid }\end{array}$ & $2.44 \times 10^{5}$ \\
\hline 25.776 & Formic acid, 2,4,6-tri-t-butyl-phenyl ester & $3.35 \times 10^{5}$ \\
\hline 26.430 & Benzoic acid & $2.09 \times 10^{5}$ \\
\hline 26.545 & 5H-1-Pyrindine & $5.30 \times 10^{5}$ \\
\hline 26.972 & 5-Hydroxymethylfurfural & $3.01 \times 10^{5}$ \\
\hline 28.302 & 1H-Inden-5-ol, 2,3-dihydro-1,1,3,3-tetramethyl-4,6-bis(1-methylethyl)- & $1.20 \times 10^{5}$ \\
\hline 28.885 & Terephthalic acid, hexyl tridec-2-yn-1-yl ester & $2.33 \times 10^{5}$ \\
\hline
\end{tabular}


Table A15. CS sample VOCs.

\begin{tabular}{|c|c|c|}
\hline Retention Time & Name & Mean \\
\hline 2.408 & Acetone & $4.15 \times 10^{6}$ \\
\hline 11.348 & Acetoin & $1.36 \times 10^{5}$ \\
\hline 13.265 & 3-Dodecyne & $2.30 \times 10^{5}$ \\
\hline 13.635 & Nonanal & $1.90 \times 10^{5}$ \\
\hline 13.751 & 1H-Pyrazole, 4,5-dihydro-5,5-dimethyl-4-isopropylidene- & $3.94 \times 10^{5}$ \\
\hline 14.021 & 1,3-Hexadiene, 3-ethyl-2-methyl- & $1.75 \times 10^{5}$ \\
\hline 14.473 & Ethyl 2-(5-methyl-5-vinyltetrahydrofuran-2-yl)propan-2-yl carbonate & $2.16 \times 10^{5}$ \\
\hline 14.686 & Ammonium acetate & $4.18 \times 10^{6}$ \\
\hline 14.929 & Furfural & $1.26 \times 10^{7}$ \\
\hline 15.367 & 2,4-Heptadienal, (E,E)- & $3.62 \times 10^{5}$ \\
\hline 15.579 & Ethanone, 1-(2-furanyl)- & $1.52 \times 10^{6}$ \\
\hline 15.874 & Benzaldehyde & $8.93 \times 10^{7}$ \\
\hline 16.143 & 1,6-Octadien-3-ol, 3,7-dimethyl- & $1.18 \times 10^{6}$ \\
\hline 16.611 & 2-Furancarboxaldehyde, 5-methyl- & $4.04 \times 10^{5}$ \\
\hline 16.850 & 4-Cyclopentene-1,3-dione & $5.89 \times 10^{4}$ \\
\hline 16.990 & 3-Cyclohexen-1-ol, 4-methyl-1-(1-methylethyl)-, (R)- & $1.11 \times 10^{5}$ \\
\hline 17.279 & 1-Cyclohexene-1-carboxaldehyde, 2,6,6-trimethyl- & $3.54 \times 10^{5}$ \\
\hline 17.432 & Butanoic acid, 4-hydroxy- & $4.79 \times 10^{5}$ \\
\hline 17.888 & Butanoic acid, 2-methyl- & $7.36 \times 10^{5}$ \\
\hline 18.152 & 3-Cyclohexene-1-acetaldehyde, $\alpha, 4$-dimethyl- & $3.44 \times 10^{5}$ \\
\hline 18.251 & L- $\alpha$-Terpineol & $1.63 \times 10^{6}$ \\
\hline 18.975 & 1, 1,5-Trimethyl-1, 2-dihydronaphthalene & $9.02 \times 10^{5}$ \\
\hline 19.875 & 2-Buten-1-one, 1-(2,6,6-trimethyl-1,3-cyclohexadien-1-yl)-, (E)- & $8.59 \times 10^{4}$ \\
\hline 20.069 & Heptanoic acid & $4.08 \times 10^{5}$ \\
\hline 20.230 & $\alpha$-Ionone & $2.65 \times 10^{5}$ \\
\hline 20.502 & Benzyl alcohol & $2.75 \times 10^{6}$ \\
\hline 20.705 & 3-Buten-2-ol, 4-(2,6,6-trimethyl-2-cyclohexen-1-yl)-, (3E)- & $2.31 \times 10^{5}$ \\
\hline 20.916 & Phenylethyl Alcohol & $1.52 \times 10^{5}$ \\
\hline 21.259 & trans- $\beta$-Ionone & $3.18 \times 10^{5}$ \\
\hline 21.740 & 2,5-Furandicarboxaldehyde & $1.40 \times 10^{5}$ \\
\hline 21.955 & Phenol & $1.57 \times 10^{5}$ \\
\hline 22.080 & 3-Furancarboxylic acid, methyl ester & $2.73 \times 10^{5}$ \\
\hline 23.699 & Eugenol & $2.11 \times 10^{5}$ \\
\hline 24.410 & Heptadecanal & $2.78 \times 10^{5}$ \\
\hline 24.993 & Phenol, 3,5-bis(1,1-dimethylethyl)- & $1.94 \times 10^{5}$ \\
\hline 25.405 & 1-(+)-Ascorbic acid 2,6-dihexadecanoate & $1.36 \times 10^{6}$ \\
\hline 26.258 & Benzoic acid & $2.30 \times 10^{7}$ \\
\hline 26.890 & 5-Hydroxymethylfurfural & $5.10 \times 10^{5}$ \\
\hline
\end{tabular}

\section{References}

1. DECRETO LEGISLATIVO 20 Febbraio 2004, n. 50 Attuazione Della Direttiva 2001/113/CE Concernente le Confetture, le Gelatine e le Marmellate di Frutta, Nonche' la Crema di Marroni, Destinate All'Alimentazione umana. (GU n.49 del 28-2-2004-Suppl. Ordinario n. 30). Available online: https://www.normattiva.it/urires/N2Ls?urn:nir:stato:decreto.legislativo:2004-2-20;50!vig= (accessed on 14 November 2019).

2. Unimac-Gherri Food Packaging Equipment. Available online: https://www.unimac-gherri.com/notizie-eeventi/203-marmellate-soluzioni-innovative-per-un-mercato-in-crescita (accessed on 14 November 2019).

3. El Hadi, M.A.M.; Zhang, F.-J.; Wu, F.-F.; Zhou, C.-H.; Tao, J. Advances in Fruit Aroma Volatile Research. Molecules 2013, 18, 8200-8229. [CrossRef] [PubMed]

4. Nieminen, T.; Neubauer, P.; Sivelä, S.; Vatamo, S.; Silfverberg, P.; Salkinoja-Salonen, M. Volatile compounds produced by fungi grown in strawberry jam. LWT Food Sci. Technol. 2008, 41, 2051-2056. [CrossRef]

5. Im, S.; Lee, M.K.; Yunc, Y.M.; Chod, S.K.; Kim, D.H. Effect of storage time and temperature on hydrogen fermentation of food waste on hydrogen fermentation od food waste. Int. J. Hydrogen Energy 2019. [CrossRef] 
6. Yildirim, R.M.; Arici, M. Effect of the fermentation temperature on the degradation of phytic acid in whole-wheat sourdough bread. LWT 2019, 112, 108224. [CrossRef]

7. Delatour, T.; Huertas-Pérez, J.F.; Dubois, M.; Theurillat, X.; Desmarchelier, A.; Ernest, M.; Stadler, R.H. Thermal degradation of 2-furoic acid and furfuryl alcohol as pathways in the formation of furan and 2-methylfuran in food. Food Chem. 2019, 303, 125406. [CrossRef]

8. Rocchi, R.; Mascini, M.; Faberi, A.; Sergi, M.; Compagnone, D.; di Martino, V.; Carradori, S.; Pittia, P. Comparison of IRMS, GC-MS and E-Nose data for the discrimination of saffron samples with different origin, process and age. Food Control 2019, 106, 106736. [CrossRef]

9. Ziółkowska, A.; Wąsowicz, E.; Jeleń, H.H. Differentiation of wines according to grape variety and geographical origin based on volatiles profiling using SPME-MS and SPME-GC/MS methods. Food Chem. 2016, 213, 714-720. [CrossRef]

10. Yang, Y.-N.; Zheng, F.-P.; Yu, A.-N.; Sun, B.-G. Changes of the free and bound volatile compounds in Rubus corchorifolius L. f. fruit during ripening. Food Chem. 2019, 287, 232-240. [CrossRef]

11. Gao, J.; Wu, B.-P.; Gao, L.-X.; Liu, H.-R.; Zhang, B.; Sun, C.-D.; Chen, K.-S. Glycosidically bound volatiles as affected by ripening stages of Satsuma mandarin fruit. Food Chem. 2018, 240, 1097-1105. [CrossRef]

12. Silva, J.S.; Damiani, C.; Da Cunha, M.C.; Carvalho, E.E.N.; Boas, E.V.D.B.V. Volatile profiling of pitanga fruit (Eugenia uniflora L.) at different ripening stages using solid-phase microextraction and mass spectrometry coupled with gas chromatography. Sci. Hortic. 2019, 250, 366-370. [CrossRef]

13. Porto-Figueira, P.; Freitas, A.; Cruz, C.J.; Figueira, J.A.; Câmara, J.S. Profiling of passion fruit volatiles: An effective tool to discriminate between species and varieties. Food Res. Int. 2015, 77, 408-418. [CrossRef]

14. Sdiri, S.; Rambla, J.L.; Besada, C.; Granell, A.; Salvador, A. Changes in the volatile profile of citrus fruit submitted to postharvest degreening treatment. Postharvest Biol. Technol. 2017, 133, 48-56. [CrossRef]

15. Wu, Q.; Tao, X.; Ai, X.; Luo, Z.; Mao, L.; Ying, T.; Li, L. Effect of exogenous auxin on aroma volatiles of cherry tomato (Solanum lycopersicum L.) fruit during postharvest ripening. Postharvest Boil. Technol. 2018, 146, 108-116. [CrossRef]

16. Xu, L.; Wang, X.; Huang, Y.; Wang, Y.; Zhu, L.; Wu, R. A predictive model for the evaluation of flavor attributes of raw and cooked beef based on sensor array analyses. Food Res. Int. 2019, 122, 16-24. [CrossRef]

17. Abbatangelo, M.; Núñez-Carmona, E.; Sberveglieri, V.; Zappa, D.; Comini, E.; Sberveglieri, G. Application of a Novel S3 Nanowire Gas Sensor Device in Parallel with GC-MS for the Identification of Rind Percentage of Grated Parmigiano Reggiano. Sensors 2018, 18, 1617. [CrossRef]

18. Núñez-Carmona, E.; Abbatangelo, M.; Sberveglieri, V. Innovative Sensor Approach to Follow Campylobacter jejuni Development. Biosensors 2019, 9, 8. [CrossRef]

19. Abbatangelo, M.; Carmona, N.; Duina, G.; Sberveglieri, V.; Núñez-Carmona, E. Multidisciplinary Approach to Characterizing the Fingerprint of Italian EVOO. Molecules 2019, 24, 1457. [CrossRef]

20. Hansen, A.-M.S.; Frandsen, H.L.; Fromberg, A. Authenticity of raspberry flavor in food products using SPME-chiral-GC-MS. Food Sci. Nutr. 2016, 4, 348-354. [CrossRef]

21. Gökbulut, I.; Karabulut, I. SPME-GC-MS detection of volatile compounds in apricot varieties. Food Chem. 2012, 132, 1098-1102. [CrossRef]

22. Cheng, H.; Chen, J.; Chen, S.; Wu, D.; Liu, D.; Ye, X. Characterization of aroma-active volatiles in three Chinese bayberry (Myrica rubra) cultivars using GC-MS-olfactometry and an electronic nose combined with principal component analysis. Food Res. Int. 2015, 72, 8-15. [CrossRef]

23. Abbatangelo, M.; Carmona, E.N.; Sberveglieri, V. Application of a novel S3 nanowire gas sensor device in parallel with GC-MS for the identification of Parmigiano Reggiano from US and European competitors. J. Food Eng. 2018, 236, 36-43. [CrossRef]

24. Abbatangelo, M.; Núñez-Carmona, E.; Sberveglieri, V. Novel equipment for food quality control: An IoT nanowire gas sensors array. Chem. Eng. Trans. 2019, 75, 25-30.

25. Sberveglieri, G. Recent developments in semiconducting thin-film gas sensors. Sens. Actuators B Chem. 1995, 23, 103-109. [CrossRef]

26. Comini, E.; Ottini, L.; Faglia, G.; Sberveglieri, G. $\mathrm{SnO}_{2}$ RGTO UV Activation for CO Monitoring. IEEE Sens. J. 2004, 4, 17-20. [CrossRef]

27. Dieguez, A.; Romano-Rodrıguez, A.; Morante, J.; Sangaletti, L.; Depero, L.E.; Comini, E.; Faglia, G.; Sberveglieri, G. Influence of the completion of oxidation on the long-term response of $\mathrm{RGTO} \mathrm{SnO}_{2}$ gas sensors. Sens. Actuators B Chem. 2000, 66, 40-42. [CrossRef] 
28. Comini, E.; Faglia, G.; Sberveglieri, G.; Pan, Z.; Wang, Z.L. Stable and highly sensitive gas sensors based on semiconducting oxide nanobelts. Appl. Phys. Lett. 2002, 81, 1869-1871. [CrossRef]

29. Sberveglieri, G.; Concina, I.; Comini, E.; Falasconi, M.; Ferroni, M.; Sberveglieri, V. Synthesis and integration of tin oxide nanowires into an electronic nose. Vacuum 2012, 86, 532-535. [CrossRef]

30. Zappa, D.; Comini, E.; Zamani, R.; Arbiol, J.; Morante, J.; Sberveglieri, G. Preparation of copper oxide nanowire-based conductometric chemical sensors. Sens. Actuators B Chem. 2013, 182, 7-15. [CrossRef]

31. Introduction to Organic Laboratory Techniques. Available online: https://www.researchgate.net/publication/ 313056682_Introduction_to_organic_laboratory_techniques_4th_ed (accessed on 2 January 2006).

32. Food additives permitted for direct addition to food for human consumption, FDA part 172-Subpart F, Flavoring Agents and Related Substances Sec. 172.515 Synthetic flavoring substances and adjuvants. Available online: https://www.accessdata.fda.gov/scripts/cdrh/cfdocs/cfcfr/CFRSearch.cfm?fr=172.515 (accessed on 27 November 2019).

33. Australia New Zealand Food Standards. Code Standard 1.2.4-Labelling of Ingredients. Available online: comlaw.gov.au (accessed on 14 November 2019).

34. Hoydonckx, H.E.; van Rhijn, W.M.; van Rhijn, W.; de Vos, D.E.; Jacobs, P.A. Furfural and Derivatives. In Ullmann's Encyclopedia of Industrial Chemistry; Wiley-VCH: Weinheim, Germany, 2007. [CrossRef]

35. Wang, Y.; Juliani, H.R.; Simon, J.E.; Ho, C.-T. Amino acid-dependent formation pathways of 2-acetylfuran and 2,5-dimethyl-4-hydroxy-3[2H]-furanone in the Maillard reaction. Food Chem. 2009, 115, 233-237. [CrossRef]

36. Scott, H.R.; Scott, L.E. Process of Treating Nut Kernels to Produce Food Ingredients. U.S. Patent US1416128A, 16 May 1922.

37. Chambers, A.; Whitaker, V.M.; Gibbs, B.; Plotto, A.; Folta, K.M. Detection of the linalool-producing NES1 variant across diverse strawberry (Fragaria spp.) accessions. Plant Breed. 2012, 131, 437-443. [CrossRef]

38. Chouhan, S.; Sharma, K.; Guleria, S. Antimicrobial Activity of Some Essential Oils—Present Status and Future Perspectives. Medicines 2017, 4, 58. [CrossRef] [PubMed]

39. Hui, Y.H. Handbook of Fruit and Vegetable Flavors; John Wiley \& Sons, Inc.: Hoboken, NJ, USA, 2010; ISBN 978-0-470-22721-3.

40. Burdock, G.A. Fenaroli's Handbook of Flavor Ingredients, 5th ed.; CRC Press: Boca Raton, FL, USA, $2005 ;$ p. 15. ISBN 0-8493-3034-3.

41. Günzler, H. Analytiker-Taschenbuch 21 (in German); Springer: Berlin/Heidelberg, Germany, 2000; p. 39. ISBN 3-540-66232-4.

42. Yao, S.-S.; Guo, W.-F.; Lu, Y.; Jiang, Y.-X. Flavor Characteristics of Lapsang Souchong and Smoked Lapsang Souchong, a Special Chinese Black Tea with Pine Smoking Process. J. Agric. Food Chem. 2005, 53, 8688-8693. [CrossRef] [PubMed]

43. Fu, X.-J.; Maimaiti, A.S.; Mou, H.-M.; Liu, G.-J. Hexanoic acid 2-(diethylamino)ethyl ester enhances chilling tolerance in strawberry seedlings by impact on photosynthesis and antioxidants. Biol. Plant. 2001, 55, 793-796. [CrossRef]

44. Gaborieau, S.; Cendres, A.; Page, D.; Ginies, C.; Renard, C.M. Variability of free and glycosylated volatiles from strawberries destined for the fresh market and for processing, assessed using direct enzymatic hydrolysis. LWT 2018, 98, 187-196. [CrossRef]

45. Mo, E.K.; Sung, C.K. Phenylethyl alcohol (PEA) application slows fungal growth and maintains aroma in strawberry. Postharvest Boil. Technol. 2007, 45, 234-239. [CrossRef]

46. Lu, H.; Wang, K.; Wang, L.; Li, D.; Yan, J.; Ban, Z.; Luo, Z.; Li, L.; Yang, D. Effect of superatmospheric oxygen exposure on strawberry (Fragaria $\times$ ananassa Fuch.) volatiles, sensory and chemical attributes. Postharvest Boil. Technol. 2018, 142, 60-71. [CrossRef]

47. Fu, X.; Cheng, S.; Zhang, Y.; Du, B.; Feng, C.; Zhou, Y.; Mei, X.; Jiang, Y.; Duan, X.; Yang, Z. Differential responses of four biosynthetic pathways of aroma compounds in postharvest strawberry (Fragaria $X$ ananassa Duch.) under interaction of light and temperature. Food Chem. 2017, 221, 356-364. [CrossRef]

48. Liu, B.; Jiao, W.; Wang, B.; Shen, J.; Zhao, H.; Jiang, W. Near freezing point storage compared with conventional low temperature storage on apricot fruit flavor quality (volatile, sugar, organic acid) promotion during storage and related shelf life. Sci. Hortic. 2019, 249, 100-109. [CrossRef] 
49. Guillot, S.; Peytavi, L.; Bureau, S.; Boulanger, R.; Lepoutre, J.; Crouzet, J.; Schorrgalindo, S. Aroma characterization of various apricot varieties using headspace-solid phase microextraction combined with gas chromatography-mass spectrometry and gas chromatography-olfactometry. Food Chem. 2006, 96, 147-155. [CrossRef]

50. Zhang, N.; Zhang, Q.-A.; Yao, J.-L.; Zhang, X.-Y. Changes of amygdalin and volatile components of apricot kernels during the ultrasonically-accelerated debitterizing. Ultrason. Sonochem. 2019, 58, 104614. [CrossRef]

51. Chen, M.-X.; Chen, X.-S.; Wang, X.-G.; Ci, Z.-J.; Liu, X.-L.; He, T.-M.; Zhang, L.-J. Comparison of Headspace Solid-Phase Microextraction with Simultaneous Steam Distillation Extraction for the Analysis of the Volatile Constituents in Chinese Apricot. Agric. Sci. China 2006, 5, 879-884. [CrossRef]

52. Cozzolino, R.; Martignetti, A.; Cefola, M.; Pace, B.; Capotorto, I.; De Giulio, B.; Montemurro, N.; Pellicano, M. Volatile metabolites, quality and sensory parameters of "Ferrovia" sweet cherry cold stored in air or packed in high $\mathrm{CO}_{2}$ modified atmospheres. Food Chem. 2019, 286, 659-668. [CrossRef] [PubMed]

(C) 2019 by the authors. Licensee MDPI, Basel, Switzerland. This article is an open access article distributed under the terms and conditions of the Creative Commons Attribution (CC BY) license (http://creativecommons.org/licenses/by/4.0/). 